NST

PUBLICATIONS

\title{
Predicting the Remaining Service Life of Concrete
}

\section{James R. Clifton}

U.S. DEPARTMENT OF COMMERCE National Instlute of Standards and Tochnology

Bullding and Fire Research Laboratory

Galthersburg, MD 20899

Prepared under the Structural Aging Program performed by Oak RIdge Natlonal Laboratory Oak RIdge, Tennessee 37831 for the

U.S. Nuclear Regulatory Commission Washington, DC 20555

U.S. DEPARTMENT OF COMMERCE Robert A. Mosbacher, Secretary NATIONAL INSTITUTE OF STANDARDS AND TECHNOLOGY

John W. Lyone, Director

QC

100

.456 



\section{Predicting the Remaining Service Life of Concrete}

\section{James R. Clifton}

U.S. DEPARTMENT OF COMMERCE Natlonal Instltute of Standards and Technology

Bullding and Fire Research Laboratory Galthersburg, MD 20899

\section{Prepared under the}

Structural Aging Program performed by Oak RIdge Natlonal Laboratory

Oak RIdge, Tennessee 37831

$$
\text { for the }
$$

U.S. Nuclear Regulatory Commission Washington, DC 20555

November 1991



U.S. DEPARTMENT OF COMMERCE Robert A. Mosbacher, Secretary NATIONAL INSTITUTE OF STANDARDS AND TECHNOLOGY

John W. Lyons, Director 

Nuclear power plants are providing, currently, about 17 percent of the U.S. electricity and it is expected that this level will increase to around 20 percent. Many of these plants are approaching their licensed life of 40 years and are not being replaced with new plants. If the operating life of the existing nuclear power plants are not extended, the nation could suffer serious electrical shortages. In an Electric Power Research Institute funded project, it was concluded that nuclear power reactors should have useful service lives substantially in excess of the original licensed years and that a generic method for verifying the continued integrity of concrete structures should be developed.

The U.S. Nuclear Regulatory Commission, and the Department of Energy's Oak Ridge National Laboratory are carrying out a program to develop a methodology for assessing the remaining safe-life of the concrete components and structures in nuclear power plants. The National Institute of standards and Technology (NIST) is contributing to this program by identifying and analyzing methods for predicting the remaining life of in-service concrete materials.

The NIST study consists of two major activities: (1) the evaluation of models which can be used for predicting the remaining service life of concrete exposed to the major environmental stressors and aging factors; and (2) the evaluation of accelerated aging techniques and tests which either provide data for service life models or which themselves can be used to predict the remaining service lives of existing concrete.

Identification and an understanding of expected degradation processes is necessary to select or, if necessary, to develop methods and models for predicting the life of affected concretes. Possible significant degradation processes for concrete structures in nuclear power facilitates are corrosion of reinforcement, sulfate attack, alkali-aggregate reactions, frost attack, leaching, radiation, salt crystallization, and microbiological attack. The first three processes in the above list are considered to be the most likely to have a serious effect on the condition of the concrete.

Methods which are often used for predicting the service lives of construction materials include i) estimates based on experience, ii) deductions from performance of similar materials, iii) accelerated testing, iv) applications of reliability and stochastic concepts, and v) mathematical modeling based on the chemistry and physics of degradation processes. Although these approaches are discussed separately in this report, they often are used in combination. The most promising methods are considered to be accelerated testing, applications of reliability 
and stochastic concepts, and use of mathematical models. Models for corrosion, sulfate attack, frost attack, and leaching were identified and analyzed. While no model was identified for distress caused by alkali-aggregate reactions, an approach for modeling the process was outlined.

In comparison to predicting the life of new concrete, few studies on predicting the remaining service life of in-service concrete have been reported. Most of the reported studies have dealt with corrosion of concrete reinforcement, reflecting the magnitude and seriousness of corrosion problems. Approaches which could be used in predicting remaining service lives are proposed and recommendations for their further development given.

Modeling of the kinetics of degradation processes is the most promising approach for predicting the remaining service life of concrete. Application of stochastic models may be limited because of the lack of adequate data bases to determine the statistical parameters. Accelerated tests do not provide a direct method for making the life predictions, but can be useful in obtaining data required for obtaining analytical solutions. 
Nuclear power plants are providing, currently, about 17 percent of the U.S. electricity and many of these plants are approaching their licensed life of 40 years. The U.S. Nuclear Regulatory Commission and the Department of Energy's Oak Ridge National Laboratory are carrying out a program to develop a methodology for assessing the remaining safe-life of the concrete components and structures in nuclear power plants. This program has the overall objective of identifying potential structural safety issues, as well as acceptance criteria, for use in evaluations of nuclear power plants for continued service. The National

Institute of standards and Technology (NIST) is contributing to this program by identifying and analyzing methods for predicting the remaining life of in-service concrete materials.

This report examines the basis for predicting the remaining service lives of concrete materials of nuclear power facilities. Methods for predicting the service life of new and in-service concrete materials are analyzed. These methods include 1) estimates based on experience, 2) comparison of performance, 3) accelerated testing, 4) stochastic methods, and 5) mathematical modeling. New approaches for predicting the remaining service lives of concrete materials are proposed and recommendations for their further development given.

Degradation processes are discussed based on considerations of their mechanisms, likelihood of occurrence, manifestations, and detection. They include corrosion, sulfate attack, alkaliaggregate reactions, frost attack, leaching, radiation, salt crystallization, and microbiological attack.

KEYWORDS: Accelerated testing; alkali-aggregate reactions; concrete; corrosion; modeling; nuclear power plants; service life; sulfate attack. 


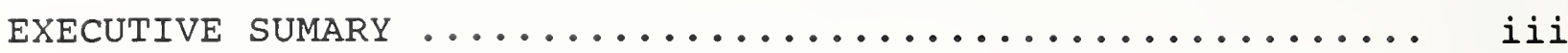





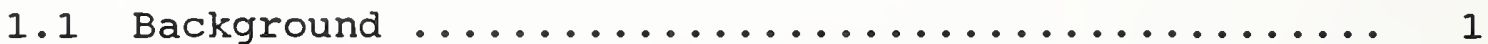

1.2 Definition and Concepts of Durability and Service



1.3 Scope and outline of Report .................. 2

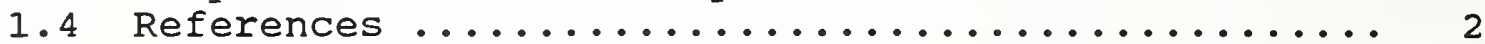

2. SIGNIFICANT DEGRADATION PROCESSES FOR CONCRETE OF NUCLEAR POWER PLANTS ..................... 4

2.1 Corrosion of Reinforcement .............. 4

2.1.1 Steel Reinforcing Bars ............... 4

2.1.1.1 Chloride Ions .................. 6

2.1 .1 .2 Carbonation ....................... 7

2.1 .1 .3 Concentration Cells ............... 8

2.1 .1 .4 stray currents .................. 9

2.1.2 Prestressing steel ..................... 9

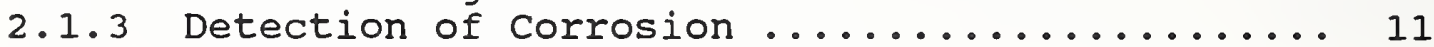

2.1.4 Corrosion in Reinforced concrete structures at Nuclear Power Facilities ............. 11

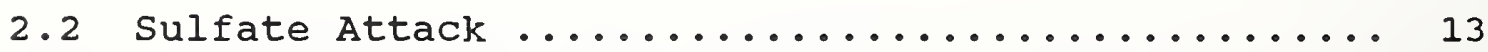

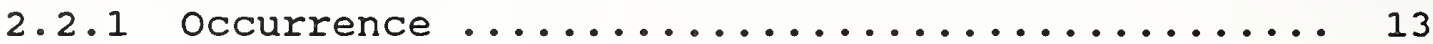

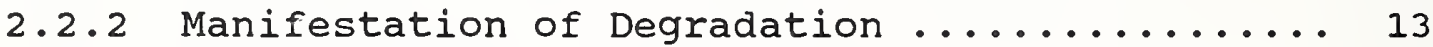

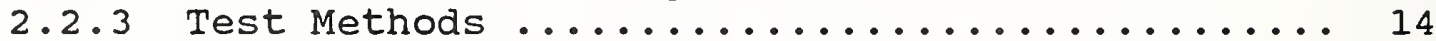

2.2 .4 Possibility of Sulfate Attack at Nuclear Power Facilities .................... 14

2.3 Alkali-Aggregate Reactions ................. 15

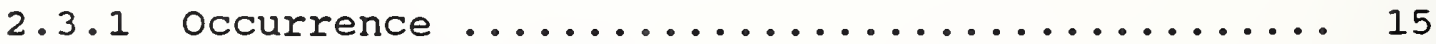

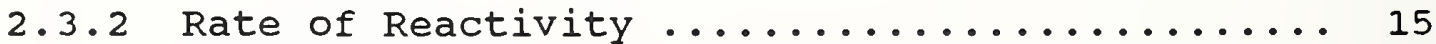



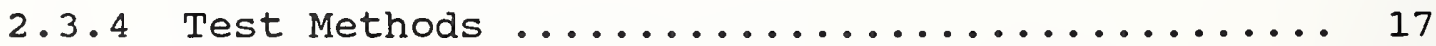

2.3.5 Possibility of and Detection of AAR in

Nuclear Power Facilities ............. 17






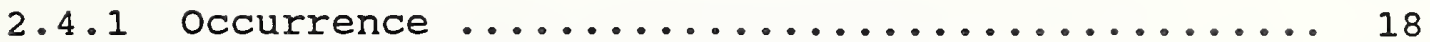

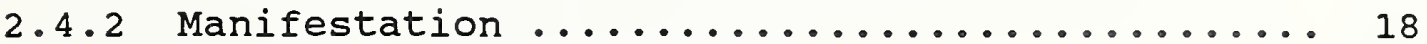

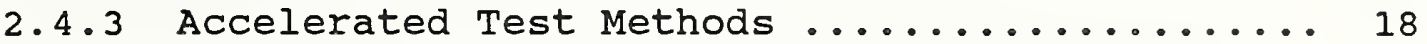

2.4.4 Possibility of Frost Attack of Concrete of Nuclear Power Facilities ................ 19



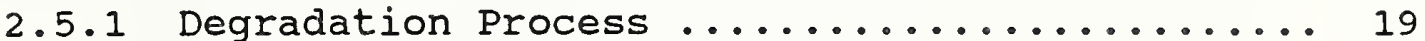

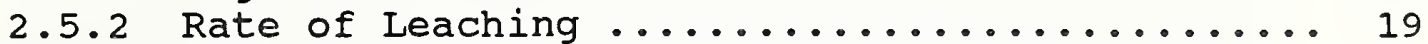

2.5.3 Possibility of Leaching Problems at Nuclear

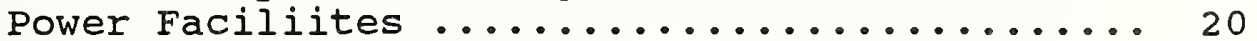

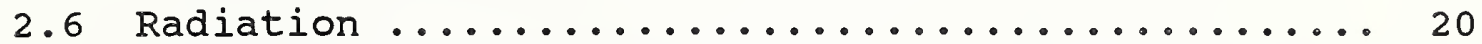

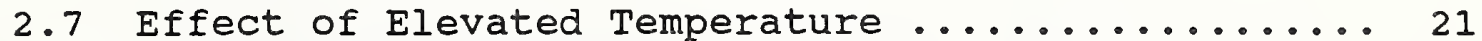

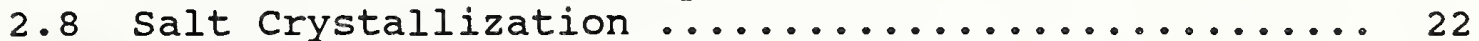

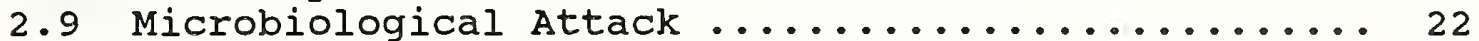



3. REVIEW OF METHODS FOR PREDICTING THE SERVICE LIFE OF NEW CONCRETE

3.1 Methods for Predicting Life of New Concrete ..... 31

3.1.1 Estimates Based on Experience ............... 31

3.1.2 Predictions Based on Comparison of Performance 31

3.1 .3 Accelerated Testing .................. 32

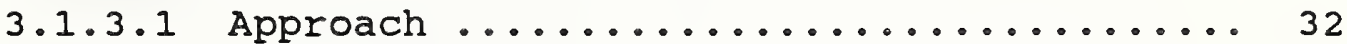

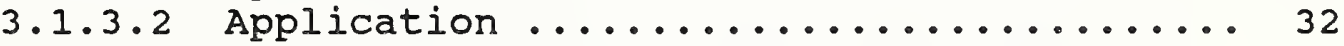

3.1.4 stochastic Methods .................. 34

3.1.4.1 Reliability Method ................. 34

3.1.4.2 Combination of statistical and

Deterministic Models .............. 37

3.2 Mathematical Modeling .................... 38

3.2 .1 Corrosion Models ...................... 39

3.2.1.1 Empirical Models by stratfull and clear. 39

3.2.1.2 Empirical Models Reported by Vesikari ... 40

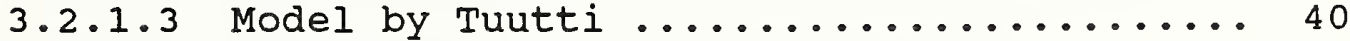

3.2 .1 .4 Model for corrosion by sea water ....... 44

3.2.1.5 Corrosion Induced by Carbonation ....... 44 
Table of Contents (Continued)

Page

3.2.1.6 Modeling Stress Corrosion Cracking (SCC)

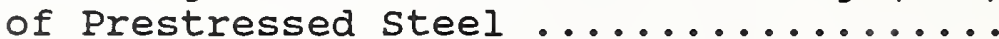

3.2 .2 Sulfate Attack .................. 47

3.2.2.1 Empirical Model ................ 47

3.2 .2 .2 Shrinking Core Model .............. 50

3.2.2.3 Mechanistic Model ............... 50

3.2.3 Alkali-Aggregate Reactions ............ 52





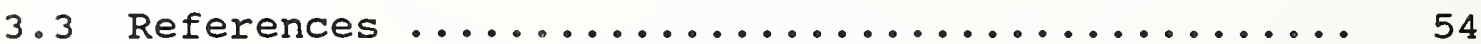

4. REPORTED METHODS FOR PREDICTING REMAINING SERVICE LIVES 59

4.1 Models .............................. 59

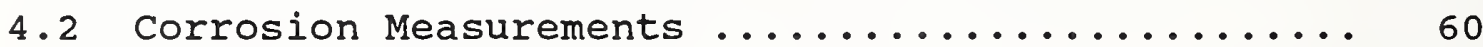

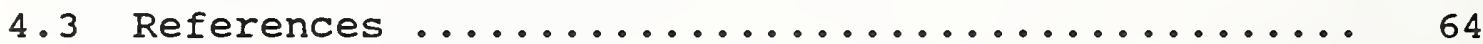

5. PROPOSED METHODS FOR PREDICTING REMAINING SERVICE LIVES 65

5.1 Time order Approach .................... 65

5.1 .1 Development of Approach ................6. 65

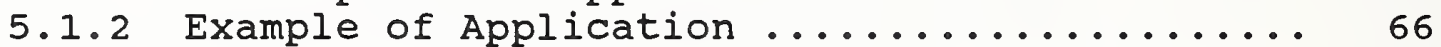

5.1.3 Recommendations for Further Development .... 67

5.2 Dealing with Cyclic Processes .............. 67

5.3 Predictions Based on Estimating Original Service

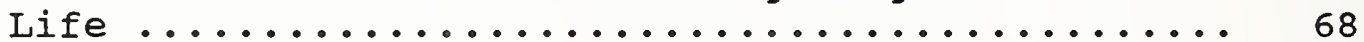

5.4 Approaches for Other Major Degradation Processes 68

5.4.1 Corrosion Propagation Period ............. 69

5.4.2 Alakali-Aggregate Reactivity ............ 69

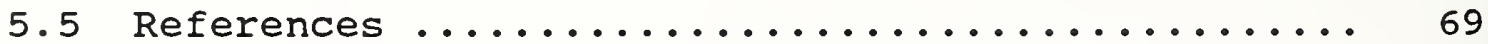

6. SUMMARY AND CONCLUSIONS $\ldots \ldots \ldots \ldots \ldots \ldots \ldots \ldots \ldots \ldots \ldots \ldots$

7. ACKNOWLEDGEMENTS $\ldots \ldots \ldots \ldots \ldots \ldots \ldots \ldots \ldots \ldots \ldots \ldots \ldots \ldots$ 
Table 1. Interpretation of Corrosion Potential Tests

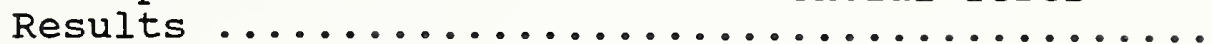

List of Figures

Figure 2.1 Examples of Some Likely Sites for Manifestation of Selected Degradation Processes. AAR Denotes Alakali-Aggregate Reactions and r.h. Denotes



Figure 2.2 Effect of Relative Humidity on Corrosion Rate of Concrete Reinforcing steel [2.3] ......... 10

Figure 3.1 Probability of Failure at Different Stress

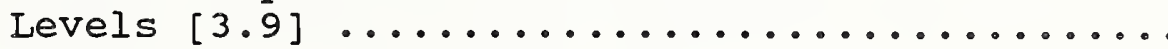

Figure 3.2 Probability-of-Failure stress Time-to-Failure (P-S-T) Diagram Showing the $10 \%$ Probability of Failure Curve $[3.9] \ldots \ldots \ldots \ldots \ldots \ldots \ldots . \ldots \ldots$

Figure 3.3 Schematic of Conceptual Model of Corrosion of Steel Reinforcement in Concrete [3.21] .......

Figure 3.4 Schematic of Reinforced concrete Element and

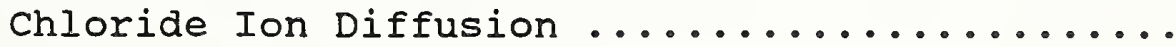

Figure 3.5 Effect of Micro-Environment in a Damp Climate on Rate of Carbonation of Concrete [3.28] ....

Figure 4.1 Effect of Corrosion on the Diameter and Cross Section of Reinforcing steel Bars, with Diameters of $10 \mathrm{~mm}$ and $20 \mathrm{~mm}[4.9] \ldots \ldots \ldots$

Figure 4.2 Reduction in Bending Moment Capacity of Concrete Beam by Corrosion of Reinforcing steel [4.9] .. 


\subsection{Background}

Nuclear power plants are providing, currently, about 17 percent of U.S. electrical power and it is expected that this level will increase to around 20 percent [1.1]. Many of these plants are approaching their licensed lives of 40 years and are not being replaced with new plants. If the operating lives of the existing nuclear power plants are not extended, the nation could suffer serious electrical shortages. In two Electric Power Research Institute funded projects, it was concluded that nuclear power plants should have useful service lives substantially in excess of the original licensed years [1.2] and that a generic method for verifying the continued integrity of concrete structures should be developed [1.3].

The Nuclear Regulatory Commission (NRC), and the Department of Energy's Oak Ridge National Laboratory (ONRL) are carrying out a program to develop a methodology for assessing the remaining safe-life of the concrete components and structures of nuclear power plants [1.4]. The National Institute of standards and Technology (NIST) is contributing to this program by identifying and analyzing methods for predicting the remaining life of inservice concrete materials.

To predict the remaining service life of concrete, information is needed on the (1) condition of the concrete, (2) major environmental stressors and aging factors, (3) processes causing the deterioration, and (4) rates of deterioration. Methods for determining the condition of reinforced concrete and the identification of major environmental stressors and aging factors encountered in nuclear power plants are being addressed in other parts of the NRC/ORNL program. The NIST project consists of two major activities: (1) the evaluation of models which possibly can be used for predicting the remaining service life of concrete exposed to the major environmental stressors and aging factors; and (2) the evaluation of accelerated aging techniques and tests which either provide data for service life models or which themselves can be used to predict the remaining service lives of existing concrete. The results of the NIST project will contribute to the development of a methodology for making reliability analyses of the safe-lives of concrete components and structures of nuclear power plants.

\subsection{Definition and Concepts of Durability and Service Life}

Durability and service life are often erroneously interchanged. The distinction between the two terms is apparent when their definitions as given in ASTM E 632 [1.5] are compared: 
durability, the capability of maintaining the serviceability of a product, component, assembly, or construction over a specified time. Serviceability is viewed as the capacity of the above to perform the function(s) for which they are designed and constructed.

service life (of building component or material), the period of time after installation during which all properties exceed the minimum acceptable values when routinely maintained.

Durability incorporates the concept of design requirements being met for a specific time (i.e., the "design life"). Service life incorporates the concept of predicting the time that the design rquirements will be met.

\subsection{Scope and outline of Report}

This report examines the basis for predicting the remaining service lives of concrete materials of nuclear power facilities. Likely significant degradation processes are described in Chapter 2. An understanding of the processes is necessary to evaluate the reliability of methods and models for predicting the life of affected concretes. Methods most often used for predicting service lives to aid in the selection of durable concrete materials are discussed in chapter 3. These methods include 1) estimates based on experience, 2) comparison of performance, 3) accelerated testing, 4) stochastic methods, and 5) mathematical modeling. Models for corrosion, sulfate attack, frost attack, and leaching are identified and analyzed. The few reported methods for predicting the remaining service lives of concrete are described in chapter 4. These methods address the corrosion of reinforcing steel. Proposed methods for predicting remaining service lives of concrete are presented in chapter 5.

\subsection{References}

1.1. D.J. Naus, "Concrete Component Aging and Its Significance Relative to Life Extension of Nuclear Power Plants," NUREG/CR-4652, U.S. Nuclear Regulatory Commission, Washington, D.C. (1986).

1.2. C.A. Negin et al., "Extended Life Operation of Light Water Reactors: Economical and Technological Review," EPRI NP2418, Vols. 1 and 2, Electric Power Research Institute, Palo Alto, California (June 1982). 
1.3. D.J. Naus, "Concrete Material systems in Nuclear Safety Related structures. A Review of factors Related to Their Durability, Degradation Detection and Evaluation, and Remedial Measures for Areas of Distress," Appendix B to longevity of Nuclear Plant systems, by I. Spiewak and R.S. Livingston, EPRI NP-4208, Electric Power Research Institute, Palo Alto, California (August, 1985).

1.4. D.J. Naus, C.B. Oland, and E.G. Arndt, "Management of the Aging of Critical safety-Related concrete structures in Light-Water Reactor Plants," in Proceeding of United States Regulatory Commission Eighteenth Water Reactor Safety Meeting, NUREG/CP-0114, Vol. 1, pp. 527-552, Brookhaven National Laboratory, Upton, New York (April 1991).

1.5. "Standard Practice for Developing Accelerated Test to Aid Prediction of the Service Life of Building Components and Materials," ASTM Designation: E 632-81. 

POWER PLANTS

Degradation processes of concrete and concrete reinforcement in nuclear power plants have been identified by Naus [2.1] and Hookham [2.2]. They include corrosion, sulfate attack, alkaliaggregate reactions, frost attack, leaching, radiation, salt crystallization, and microbiological attack. With the exception of corrosion, the degradation processes are likely to be localized and depend on the micro-environments (Fig. 2.1). Corrosion of reinforcement, sulfate attack, and alkali-aggregate reactivity are considered to be the most likely to have a serious effect on the condition of concrete of nuclear power plants and thus are discussed in more detail than the other degradation processes. The following discussions of the degradations processes are directed towards analyzing their possible occurrence in nuclear power facilities, their manifestations, and detection.

\subsection{Corrosion of Reinforcement}

The structural reinforcement in the concrete of nuclear power plants consists of steel reinforcing bars and prestressing tendons. The electrochemical corrosion of either type of reinforcement is usually caused by a change in their environments leading to the development of cathodic and anodic sites with corrosion current flowing between the sites. Significantly more corrosion problems are encountered with steel reinforcing bars than with steel tendons, probably because of the corrosion protection measures used with prestressing tendons.

\subsubsection{Steel Reinforcing Bars}

Portland cement concrete normally provides an internal environment which protects reinforcing steel from corrosion. The high alkaline environment ( $\mathrm{pH}>12.5)$ in concrete results in the formation of a tightly adhering film (gamma iron (III) oxide) which passivates the steel and thereby protects it from corrosion. If the passivating layer is corrupted, corrosion can take place. The electrochemical corrosion of steel involves the oxidation of iron at anodic and the reduction of oxygen at cathodic sites, with the overall cell reaction being:

$$
\mathrm{Fe}+1 / 2 \mathrm{O}_{2}+\mathrm{H}_{2} \mathrm{O} \rightarrow \mathrm{Fe}(\mathrm{OH})_{2} \text {. }
$$

other subsequent reactions occur with $\mathrm{Fe}(\mathrm{OH})_{3}$ being formed. It precipitates as $\mathrm{FeO} \cdot \mathrm{OH}$ which gives the characteristic rust color. Equation (1) indicates that both water and oxygen must be present for the corrosion to occur. With only water and oxygen present, however, the reaction proceeds very slowly and with good quality 


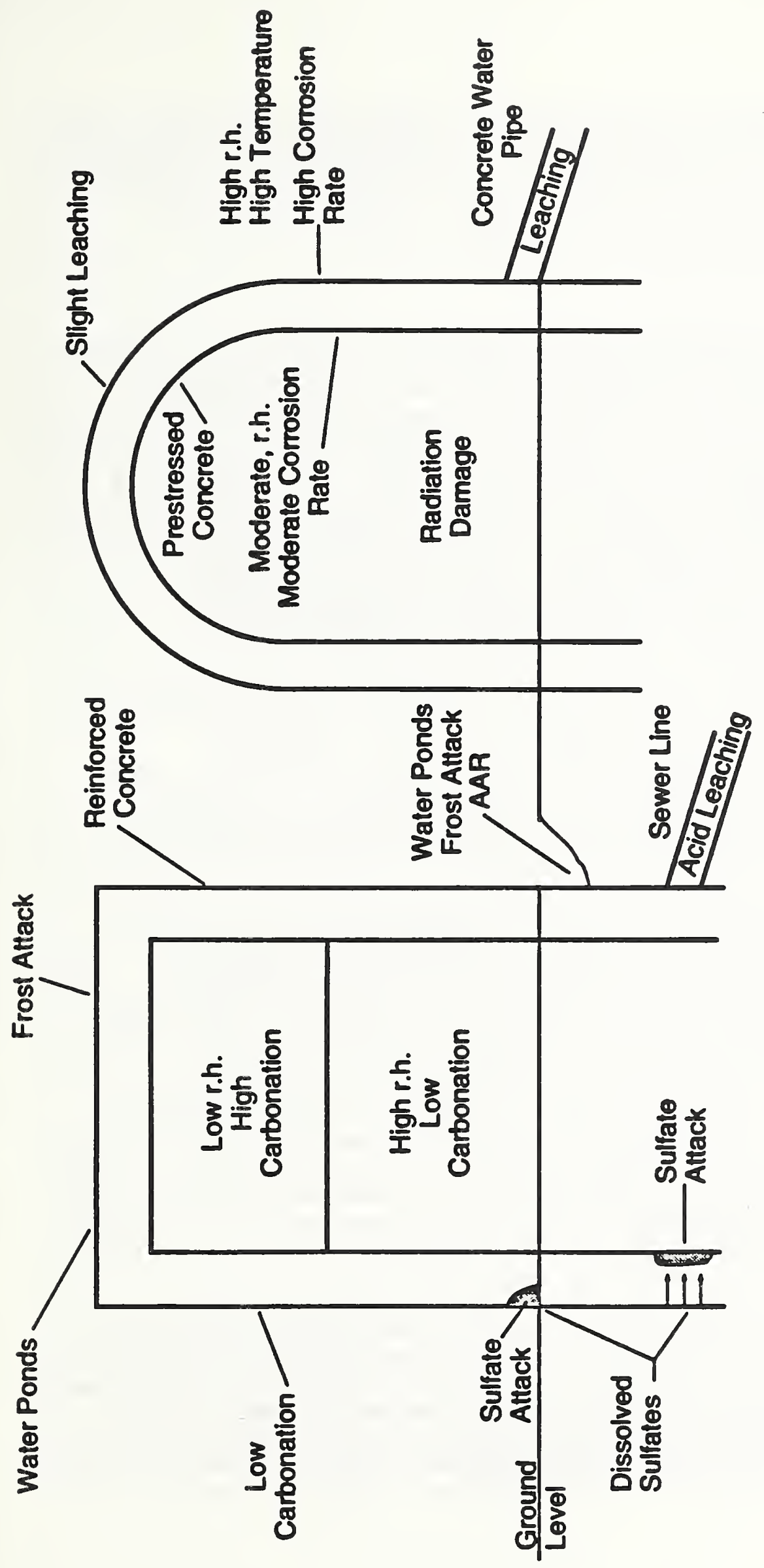

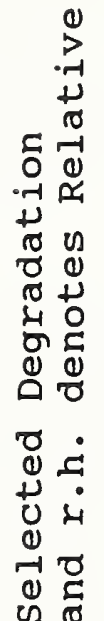

แ

동거

- 0

$+\pi$

$\downarrow \simeq$

in

过

-

ᄃ व

तิ

늘

40

운

ט

ฮั

in

구요

ज政

ญ

的发

虫

is

थै थे

다 $n$

음 0

E

옹

四呈

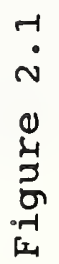


concrete the resulting rate of corrosion may be very small under normal environmental conditions [2.3]. Accelerated corrosion of steel reinforcement can be induced by chloride ions, carbonation of the concrete, stray currents, or by the development of concentration cells.

\subsubsection{Chloride Ions}

Chloride ions are considered to be the major cause of premature corrosion of steel reinforcement in many structures and could induce corrosion in the concrete of nuclear power plants. Chloride ions are common in nature and small amounts are usually unintentionally contained in the $\mathrm{mix}$ ingredients of concrete. Chloride ions also may be intentionally added, most often as a constituent of accelerating admixtures. The sources of chloride ions which are causing the most problems, however, are deicing salts (usually calcium chloride) and sea water. In addition to natural deposits of chloride salts, groundwater may be contaminated with chloride ions coming from runoff water, e.g., from bridges or pavements treated with deicing salts.

Only in the cases of i) nuclear power plants located near seashores, $i i)$ the use of chloride-containing admixtures to accelerate the hardening of concrete, or iii) concrete constituents containing appreciable chlorides, should chloride ions be found widely distributed in the concrete structures. otherwise, any chloride ions should be localized in the foundation, mud slab, or concrete elements immediately above grade.

The chemistry of the pore solution in concrete was shown by Hausman [2.4] to influence the initiation of corrosion by chloride ions. In studies carried out in sodium hydroxide solutions and saturated calcium hydroxide solutions, he found evidence for a relationship existing between the chloride ion concentration necessary to induce corrosion (threshold concentration) and the activity of the hydroxide; with the threshold level significantly decreased as the pH is lowered. For example, at a pH of 13.2 more than $8000 \mathrm{ppm}$ of chlorides ions were required to induce corrosion, while at a pH of 11.6 around $71 \mathrm{ppm}$ of chloride ions were sufficient to induce corrosion. The $\mathrm{pH}$ of concrete can be reduced by either carbonation or by water leaching of the alkaline constituents of concrete.

Because of the seriousness of the corrosion problem caused by chloride ions, models have been developed to predict the service life of reinforced concrete exposed to chloride ions. These models are reviewed in Chapter 3. However, standard accelerated tests to predict the performance of reinforced concrete in a chloride ion environment have not been developed. The Federal Highway Department [2.5] developed a ponding test to evaluate the effect of concrete variables on corrosion. AASHTO T259-80 [2.6] 
is used to evaluate the resistance of concretes to chloride ion penetration. AASHTO T277, "Rapid Determination of Chloride Permeability of Concrete," [2.7] is used to compare the performances of different concretes to chloride penetration driven by a DC voltage. None of these methods provides reliable and rapid means for determining the diffusion coefficient of chloride ions in concrete, which is needed to solve the service life models [2.8].

Several methods have been developed for the rapid field detection of chloride ions [2.9]. Schupack [2.10] described a method in which the chloride ion, in a solution extracted from concrete with acid, is determined using a chloride ion electrode. Jang and Iwasaki [2.11] have developed a color indicator method for the visual identification of chloride ion distribution in concrete. The method does not provide a quantitative assessment of the chloride contents, but it does provide information on the relative distribution of chlorides in the vicinity of reinforcing bars. A non-destructive test technique using a neutron probe for determining the chloride contents of porous materials has been reported by Livingston, et al. [2.12]. Using this technique, it appears feasible to inspect concrete non-destructvely for the presence of chloride ions.

\subsubsection{Carbonation}

Carbonation of concrete can reduces its alkalinity sufficiently to depassivate the steel and initiate corrosion. carbonation involves the reaction of gaseous carbon dioxide with calcium hydroxide of concrete to form calcium carbonate. If fully carbonated, the $\mathrm{pH}$ of the concrete is reduced to around 9 at which pH steel is susceptible to corrosion [2.3]. Also, if the depth of carbonation extends to the reinforcing steel, then the chloride ion threshold concentration can be significantly reduced. The rate of carbonation is usually described by a equation with a $t^{1 / 2}$ time dependence [2.13]. The rate and extent of carbonation depends on the environmental relative humidity, reaching a maximum at 50\% relative humidity [2.13]. Diffusion of gaseous carbon dioxide takes place several orders of magnitude more rapidly though air than through water. If the pores of concrete are saturated with water, the amount of carbonation occurring will be negligible [2.14]. In most cases, the time needed to carbonate $20 \mathrm{~mm}$ of high-quality concrete is reported $[2.15,2.16]$ to be of the order of tens of years, and the penetration rate of carbon dioxide rapidly falls well below a $\mathrm{mm} /$ year soon after construction. Brown [2.17] cafried out a field survey of 437 structures and found that a $t^{1 / 2}$ model significantly overestimates the depth of carbonation. Carbonation can be a serious problem, however, i) with high water-to-cement ratio concrete and $i i)$ if the reinforcing steel is closer to the concrete surface than recommended in building codes such as ACI 
318 "Building Code Requirements for Reinforced Concrete" [2.18]. Also, high temperatures, such as those which occur in Middle East countries, are reported to increase the severity of corrosion attributed to carbonation [2.19].

An accelerated test for predicting the rate of carbonation of concrete was reported by Ho and Lewis [2.20]. They found that the depth of carbonation of a series of concretes exposed to a laboratory atmosphere of $4 \%$ carbon dioxide for one week was approximately that obtained after one year. However, depths of carbonation of concretes exposed outdoors were less than the laboratory specimens, which was attributed to the effects of rain reducing the diffusion of $\mathrm{CO}_{2}$. The design and development of a curing apparatus and system for studying the kinetics of the carbonation of concrete has been reported [2.21].

The depth of carbonation is usually measured by using a phenolphthalein indicator solution [2.22]. The spray-applied indicator turns a bright magenta where the concrete has a pH of 9 or greater, indicative of non-carbonated concrete, while remaining colorless in carbonated concrete. If the depth of carbonation in a specimen varies by an order of magnitude, the use of thermal analysis methods to determine the depth of carbonation is recommended [2.23].

In nuclear power plants, carbonation is most likely to be a problem with the inside concrete surfaces, especially those which are exposed to low humidities and elevated temperatures.

\subsubsection{Concentration cells}

The formation of concentration cells can result in regions on the reinforcing steel having sufficient differences in their electrical potential to support corrosion $[2.24,2.25]$. concentration cells are formed when at least two sites on a reinforcing bar are in contact with different substances or the same substance in different concentrations. For example, a difference in oxygen concentration along a reinforcing bar may result in the development of anodic and cathodic sites. The rate of corrosion by concentration cells is usually slow but can be accelerated by increased temperatures and relative humidities. For example, the rate of electrochemical corrosion is doubled by a temperature increase of $10^{\circ} \mathrm{C}$. The optimum relative humidity for corrosion is around $95 \%$ and is some 4 orders of magnitude greater than at a r.h. of $80 \%$ (Fig. 2.2). The corrosion rate decreases rapidly at relative humidities above $95 \%$ as the pores become saturated with water [2.3]. Therefore, it is conceivable that significant corrosion of steel reinforcement could occur in concrete in the absence of chloride ions, carbonation, or stray currents. 


\subsubsection{Stray Currents}

stray currents may be a potential problem with reinforced concrete structures in nuclear power plants in contact with the ground or with sea water if DC producing devices are present. Stray currents can be defined as currents that follow paths other than the intended circuit [2.26]. They have been reported [2.27] to be capable of accelerating the corrosion of reinforcing steel. Induced currents from cathodic protection devices have been found in laboratory studies to soften concrete at the rebar interface and, thereby, reduce the bond strength between reinforcing bars and concrete [2.28] The most common sources of stray currents are electrical railways, electroplating plants, and cathodic protection systems [2.26]. Cathodic protection systems are often used to protect underground metal pipes transporting petroleum products and natural gas.

Electrical equipment which is not properly grounded can produce stray currents in concrete structures. Also, cathodic protection systems can cause corrosion of reinforcement not connected to the system. A method for controlling stray currents in metro railways, which could be used for ungrounded DC equipment, is described by Vernon [2.29].

Although recognized as a problem, no reports on the effect of stray currents on the service life of reinforced concrete were found. Relationships could be developed for predicting the effect of stray currents on service life if the efficiency of stray currents in causing corrosion was known. For example, in a laboratory study using a bridge model [2.27], it was found that only $0.01 \%$ of the stray current passing through sea water entered the reinforced concrete where it could cause corrosion.

\subsubsection{Prestressing steel}

Prestressing steel tendons are in principle susceptible to the same corrosion problem as steel reinforcing bars; however, because they are protected by corrosion inhibitor and placed in ducts, few problems have been observed [2.30]. Schupack [2.31] reviewed corrosion in post-tensioned concrete construction. He described some 28 cases of corrosion failure occurring in North America, Western Europe, and Japan. Feld [2.32] noted that some problems were also encountered in Eastern Europe and Asia but that compared to the number of existing structures, the number of incidents is small.

Few corrosion studies on prestressing steel were disclosed in the review. Studies have been carried out on the effectiveness of corrosion inhibitors [2.33] and on aqueous solutions and stresses on corrosion [2.34] stress corrosion cracking (SCC) of prestressed steel was reviewed and investigated by Ranganatham 


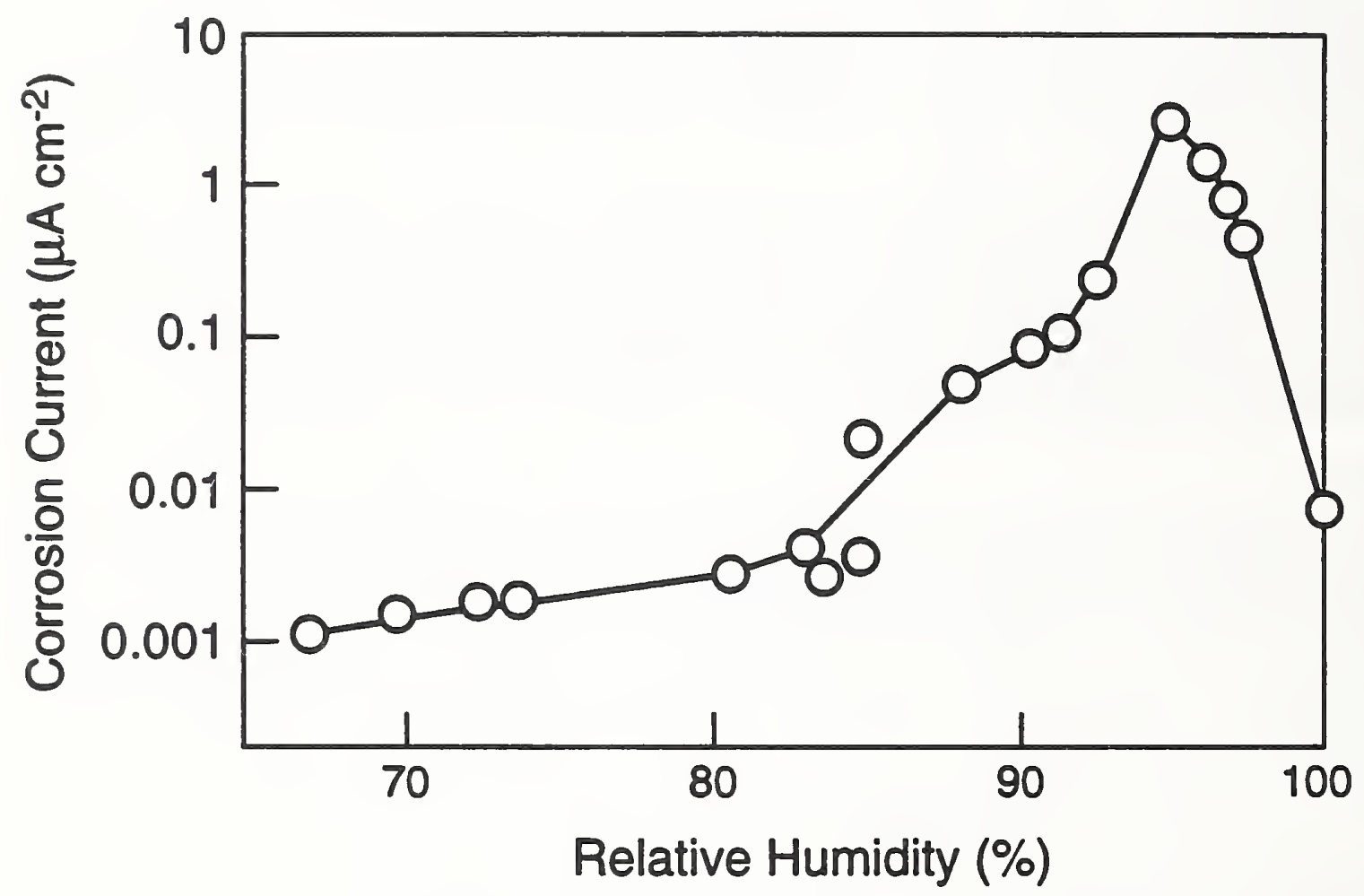

Figure 2.2 Effect of Relative Humidity on Corrosion Rate of concrete Reinforcing Steel [2.3]. 
[2.35]. He found that prestressing wires were highly susceptible to stress corrosion cracking in sulfide solutions.

\subsubsection{Detection of Corrosion}

The most common method of detecting corrosion in reinforced concrete is the observation of cracking and/or spalling of concrete accompanied by rust stains. Measurements of the electrode potential of reinforcing steel are used to determine if corrosion has occurred. ASTM C 876 [2.36] gives the procedures for carrying out the test. Based on the measured potential, the probability of corrosion is predicted (Table 2.1). Escalante [2.37] found that electrode potential measurements do not give reliable information on the rates of corrosion or if corrosion is active. Also, elevated temperature and carbonation can affect the corrosion potentials. If rates of corrosion are needed, polarization resistance measurements should be made. The polarization method is more complex than making electrode potential measurements. It involves the use of three electrodes and polarizing the open circuit potential of the reinforcing steel by $10 \mathrm{Mv}$ and measuring the applied current. The slope of the plot of change in voltage to the change in applied current $(\Delta E / \Delta I)$ is used in calculating the corrosion current [2.38]. At present a standard method for carrying out resistance polarization measurements on reinforced concrete has not been established. A computerized portable system for carrying out the measurements in the field was developed by Escalante, et al. $[2.39]$.

\subsubsection{Corrosion in Reinforced Concrete Structures at Nuclear Power Facilities}

Corrosion is likely to be the most common serious degradation problem with reinforced concrete at nuclear power facilities [2.2]. Corrosion can proceed very rapidly when chloride laden concrete is subject to a high relative humidity (but is not fully saturated). Corrosion induced by carbonation is a significantly slower process than corrosion induced by chloride ions, and in good quality concrete it should require several decades to be manifested. Corrosion by stray currents and concentration cells should be random processes. However, corrosion by stray currents could proceed rapidly, i.e., in a few years cracking of concrete could be observed.

Corrosion can significantly reduce the load capacity of reinforcement as well as result in the cracking and spalling of concrete, thereby reducing its effectiveness as a barrier. Because of the susceptibility of steel to corrosion and the large amount of reinforcement used in containments, corrosion is considered to be the degradation process of greatest concern for nuclear power facilities. 
Table 2.1. Interpretation of corrosion Potential Test Results ${ }^{a}$

Electrode Potential $(\mathrm{mV})^{b} \quad$ Probability of Presence of corrosion

$$
\begin{array}{ll}
-350 & 90 \% \\
-200 \text { to }-350 & 50 \% \\
>-200 & 10 \%
\end{array}
$$

a "Standard Test Method for Half-Cell Potentials of Uncoated Reinforcing steel in Concrete," ASTM Designation C 876 [2.367].

b. Half-cell potential of reinforcing steel relative to copper/copper sulfate reference electrode. 


\subsection{Sulfate Attack}

\section{2 .1 Occurrence}

Probably the most widespread and common attack of concrete in contact with soil involves sulfates. Sulfate attack of concrete can be very deleterious resulting in cracking of concrete and in severe cases its disintegration. Naturally-occurring sulfates of sodium, potassium, calcium, and magnesium are sometimes found in groundwaters and soils, especially when high amounts of clay are present. Sulfate attack has occurred in several regions of the United states, and is a particular problem in arid regions, such as the Northern Plains area and in the southwestern states. It is also a problem with concrete structures exposed to seawater or sulfate-bearing inland waters [2.40] The possible effect of sulfates from acid precipitation on concrete has not been determined. However, the recent report from the National Acid Precipitation Assessment Program [2.41] indicates that acid precipitation is not a serious problem with building stone.

If concrete is exposed to cycles of wetting by sulfate containing water and drying, the deposited sulfates may accumulate in the concrete at a concentration higher than that dissolved in the water [2.42]. Often the most severe sulfate attack occurs when one surface of a concrete element is exposed to sulfates and another surface is exposed to a drying environment, e.g., basement walls and floors, slabs-on-grade [2.43].

\subsubsection{Manifestation of Degradation}

The nature of the manifestation of sulfate attack depends on the exposure conditions. If the concrete element is essentially continuously immersed in sulfate-containing water, a softening process takes place [2.44] as the sulfates penetrate into the concrete. The effect area is behind the sulfate-moving interface and its depth is proportional to the depth of the interface. The softening process results in an reduction of the mechanical properties of the concrete, e.g., its load carrying capacity $[2.45,2.46]$. Assuming that the concrete is essentially continuously immersed in the sulfate-bearing water, the process is likely to be diffusion controlled.

If the concrete is exposed to cycles of wetting and drying associated with a sulfate-containing water, the sulfates will be concentrated near free concrete surfaces, and these surface layers are susceptible to disintegration. The disintegration could be preceded by the development of pattern cracking [2.42]. The reduction in load carrying capacity is proportional to the depth of the disintegration. Studies by the U.S Bureau of Reclamation [2.47] indicate that if the wet and dry cycling takes place daily, the accompanying degradation process is more rapid than that associated with continuous immersion. Wetting and 
drying process would likely involve the transport of sulfates into the concrete by a complex combination of convection, diffusion and absorption.

\section{2 .3 Test Methods}

In a recent review of sulfate attack on concrete, cohen and Mather [2.48] concluded that limited confidence can be placed in the reliability of existing standard tests and models to predict the performance and service life of concrete subjected to sulfate attack. They believe that a major problem with the current standard accelerated tests is the lack of simulated field conditions. For example, ASTM C 1012 [2.49] is used to compare the resistance of different cements to sulfate attack by measuring the expansion of mortar bars immersed in a 5\%, by weight, sodium sulfate solution. This test, therefore, only simulates a concrete element immersed in sulfate-containing water. The performance of a cement in a concrete exposed to wetting and drying cycles with a sulfate-bearing water may be significantly different than that predicted by ASTM C 1012 . Evidence of such a lack of correlation is given by the long-term field study performed by the Portland Cement Association [2.50]. For example, it was observed that a concrete containing granulated slag as a partial replacement for portland cement did not perform as well as predicted based on immersion testing.

Although sulfate attack involving wetting and drying cycles appears to be as least as common as the attack under immersion conditions, a standard test method for the wetting and drying process has not been developed. Some research is being carried at W.R. Grace [2.51] and at NIST to develop such a test.

\subsubsection{Possibility of Sulfate Attack at Nuclear Power Facilities}

Sulfate attack appears to be a localized problem in the United states and is most likely to effect those concrete elements of nuclear power facilities exposed to soils and sulfate-bearing waters, especially at locations where the sulfates are concentrated by evaporation of solutions. Another component of nuclear power facilities which may be exposed to deleterious amounts of sulfates are concrete pipe through which sewage and sulfate-bearing water pass.

ASTM Type II portland cement appears to have been used in the construction of nuclear power facilities [2.2], which should protect concrete if the amounts of sulfates are no more than 0.20 percent in soils and $1500 \mathrm{ppm}$ in water [2.40]. Even if the concentration of sulfates in the soil or water is less than the above sulfate limits, it is conceivable that the limits could be exceeded in the concrete by evaporation of the sulfate solution. 
Alkali-aggregate reactions (AAR) are different from those previously discussed in that the reactive components are usually internally contained in concrete and, therefore, are not dependent on the diffusion of an aggressive solution into the concrete. However, for appreciable amounts of swelling to occur a plentiful source of water is needed. Several forms of AAR are known, depending on the mineralogy of the aggregate, which can result in deleterious expansion. AAR can affect both siliceous and carbonate aggregates. Although the mechanisms are different for these two general types of aggregates, their results are the same. An excellent source of information on the different forms of AAR is the ACI Guide to Durable concrete [2.40].

\section{3 .1 Occurrence}

It appears that all aggregates react to some degree with alkalies in cement. In the majority of cases the reactions are beneficial (e.g., increasing the bond between aggregate and hydrated cement paste) or innocuous. In some cases, however, the reactions result in the formation of expansive products which can cause serious cracking of the concrete. The expansion is attributed to the imbibition of water by the reaction products. Expansive AAR are known to occur with certain siliceous aggregates and certain dolomitic limestone aggregates. Alkali-silica is the most common and well studied reaction and has been found to occur in numerous places in the United States [2.52] with the greatest abundance of alkali-silica rocks being found in the western states. Slow reacting siliceous aggregates have been found in the eastern states. Alkali-carbonate reactions have occurred in some midwestern and eastern states [2.40].

Because the deleterious expansion phase of AAR involves the imbibition of water, early indications of such processes are observed at places where water can readily enter the concrete. For example, in pavements and slabs on-grade, AAR is most likely to be first observed at joints, edges, and cracks, and also at locations where water can pond. Concrete water pipes, columns and foundations immersed in water or exposed to groundwater, and exterior surfaces of structures where water can pond, also, may exhibit early signs of AAR.

\subsubsection{Rate of Reactivity}

Alkali-aggregate reactions may proceed rapidly (several months to a few years) or much slower (e.g., early signs observed only after some 20 to 25 years [2.53-2.55]). Reasons for the delayed reaction are not unequivocally known.

Even if reactions between alkalies and aggregate take place within a year or two, cracking may not be manifested for many 
years if there is not sufficient water available to sustain the swelling process. If, however, the concrete is suddenly exposed to a plentiful supply of water, e.g., a flood or broken water pipe, then a rapid expansion could take place. AAR is a self limiting process because as more water is imbibed the driving force to imbibe additional water decreases and the expansion tends to level-off [2.56]. Further research is required, however, to develop models which can be used to predict the length of time that AAR will be active.

\subsubsection{Effects of AAR}

If cracking results from $A A R$, it can range from being cosmetic (in most cases) to resulting in structural failure (uncommon) of concrete. In unreinforced concrete, AAR results in pattern cracking while in reinforced concrete long cracks parallel to the direction of longitudinal reinforcement are observed with random thin cracks bridging the longitudinal cracks. Cracking of concrete, even though not causing structural collapse, can significantly increase its permeability.

Stresses caused by AAR appear to be low, rarely exceeding 6 to 7 $\mathrm{mPa}$ [2.56]. Reinforcement is effective in reducing the width of the cracks and most of the problems are associated with lightly reinforced or unreinforced concrete structures such as dams. Interestingly, the concrete of some massive dams constructed in the U.S. western states have exhibited expansions due to AAR for some 30-40 years and then the expansion terminated without causing structural problems [2.57].

In a study on the effects of alkali-silica reactions (ASR) Swamy [2.58] concluded that it is unlikely that structures will collapse because of ASR. The most significant effect of ASR will be on serviceability and even moderate expansions of 0.2 to $0.3 \%$ could create significant structural distress when the effect of AAR are superimposed on serviceability loads. In developing repair criteria for concrete subjected to ASR, Doran and Moore suggested [2.59] that expansions on the order of $0.4 \mathrm{~mm} / \mathrm{m}$ should not be of concern for reinforced concrete. Expansions in the range of 0.6 to $0.9 \mathrm{~mm} / \mathrm{m}$, while not significantly affecting the compressive strength, could reduce the tensile strength sufficiently to adversely affect behavior in shear and bond, but still should be within normal safety factors. If expansions are in excess of $0.9 \mathrm{~mm} / \mathrm{m}$ a detailed structural appraisal should be performed. In many ways, the effects of cracks caused by AAR are similar to those caused by other processes, such as by overloading or other internal expansive processes. Cracks caused by AAR should be regarded as being active, unless it is observed that over some years the cracks have been dormant in the presence of water. 


\subsubsection{Test Methods}

Laboratory testing of silica-containing aggregate has in the past consisted of petrographic examination, ASTM C 295 [2.60], the mortar bar expansion test ASTM C 227 [2.61], and the chemical test, ASTM C 289 [2.62], or their combination. However, these tests may not provide an adequate basis for predicting the longterm expansive characteristics of concrete structures containing slowly reacting siliceous aggregates [2.63]. A recently

developed test which appears to have the potential of being more reliable in predicting the reactivity of siliceous aggregate is the proposed ASTM P 214 "Test Method for Accelerated Deleterious Expansion of Mortar Bars Due to Alkali-silica Reaction." [2.64]. The test is based on the research of oberholster and Davies [2.65]. The test involves crushing of aggregate to a fine size, making mortar bars, exposing the bars to a $1 \mathrm{~N}$ solution of $\mathrm{NaOH}$, at $80^{\circ} \mathrm{C}$, and making expansion measurements over 14 days.

A procedure for evaluating the potential AAR of carbonate rocks was developed by Rogers [2.66]. He proposed that the determination of the Cao ratio and alumina or insoluble content of aggregates could be used to screen potentially alkalicarbonate expansive aggregates from those which are nonexpansive. carbonate aggregates which are potentially reactive would be tested by traditional expansion tests using $\mathrm{NaOH}$ solutions. ASTM C 586 [2.67] is often used to test the potential alkali reactivity of carbonate rocks.

\subsubsection{Possibility of and Detection of AAR in Nuclear Power Facilities}

Many nuclear power facilities are nearly 40 years old and by now the occurrence of AAR should be detectable, either by the identification of reaction products by petrographic analysis or by the observation of cracks. Even after 40 years the possibility of latent AAR, because of the lack of water, should be considered and appropriate petrographic analysis performed. While being the exception, it is possible that a slowly reacting siliceous aggregate, which passed the ASTM standard tests in effect at time of selection, could actually have been reactive.

A method has been developed for field identification of ASR [2.68-2.70]. It involves the application of a uranyl acetate solution to the surface of concrete. ASR gel absorbs the uranyl ion, which give off yellowish-green fluorescent light when exposed to ultraviolet light.

An accepted field method for detecting alkali-carbonate reactions is not available. 


\subsection{Frost Attack}

\subsubsection{Occurrence}

Frost damage occurs when a damp concrete is exposed to cycles of freezing and thawing. The concrete does not need to be fully saturated with water for damage to occur as the critical level of saturation is around 85 percent for most concretes [2.71]. Freezing and thawing damage is a serious problem for exposed concrete in the northern states, resulting in its cracking and reduced service life. The resistance of concrete in freezing environments to frost attack is largely controlled by the amount of entrained air and the spacing of entrained air bubbles. However, even air entrained concrete can undergo frost damage in the uncommon situation where the entrained air volume becomes saturated [2.72].

\subsubsection{Manifestation}

Both the mortar matrix and certain coarse aggregates are susceptible to frost attack. Degradation of the mortar matrix indicates the lack of sufficient entrained air or too large a spacing factor. It is manifested by the development of pattern cracks and eventually by the disintegration of the concrete. Some aggregates have an appreciable volume of fine pores and if they are critically saturated, cracking can occur through ice formation [2.73]. D-cracking in concrete pavements is attributed to the freezing of water in frost-susceptible aggregates.

\subsubsection{Accelerated Test Methods}

Several different methods are available for evaluating the frost resistance of concrete. The accelerated test which is most often used is ASTM C 666 [2.74]. It involves short cycles of freezing and thawing of saturated concrete specimens and measuring the resonance sonic frequency to monitor degradation. This test has been criticized because the test conditions do not simulate normal in-service freezing conditions. As described in section 3.5.4, this test has been incorporated into a model for predicting the service life of concrete degraded by frost action [2.75]. ASTM C 671 [2.76] is a dilation test which is considered to more closely simulate actual in-service conditions. However, the results with ASTM C 671 are sensitive to the moisture content of the concrete prior to test and it requires more time to perform than does ASTM C 666. A critical saturation test has been developed by Fagerlund [2.72]. In this test, absorption studies are carried out to determine the approximate time required for concrete to reach the critical degree of saturation. The frost resistance at a given time is the difference between the critical saturation and the actual level of saturation at that time. 
2.4.4 Possibility of Frost Attack of Concrete of Nuclear Power Facilities

Horizontal concrete surfaces such as pavements, walkways, roofs, sills, and other surfaces where water can remain in contact with the concrete for some time are especially susceptible to frost damage. Also, concrete structures or elements partially immersed in seawater or inland water could be susceptible to frost attack above the water line, Thus, certain concrete components of nuclear power facilities could be susceptible to frost attack.

\subsection{Leaching}

\subsubsection{Degradation Process}

Leaching involves the degradation of concrete by the dissolution of the soluble constituents of a material. Considering the common constituents of portland cement paste, alkali salts are the most soluble followed by calcium hydroxide. The solubility of silica oxide is very low so that the decomposition rate, through dissolution, of the calcium silicate hydrate is very slow $[2.77]$.

Acidic waters will attack concrete through the dissolution and neutralization of the alkali and calcium hydroxides. Rate and extent of the acid leaching is dependent on the acidity of the water, i.e., leaching increases as the $\mathrm{pH}$ decreases. The pattern of the acid-eroded surfaces depends on the aggregate mineralogy. When immersed in sulfuric acid, limestone-aggregate concrete erodes to a relatively smooth surface with no detritus, while siliceous-aggregate concrete produces an irregular surface with considerable aggregate detritus [2.78].

Calcium-absorptive acidic soils are known to be aggressive to concrete [2.79]. The potential leaching capabilities of ground waters can be related to their Langelier Indexes (also called Saturation Index). The Langelier Index is related to the total solids, total alkalinity, $\mathrm{pH}$, and calcium content of the water [80]. A positive index indicates that calcium carbonate will be precipitated; a negative index indicates that the water is limedeficient (soft water) and is capable of dissolving calcium from hardened cement paste.

\subsubsection{Rate of Leaching}

The depth of penetration of water into the concrete is largely controlled by the permeability of the concrete and the hydrostatic pressure of the water. Assuming a constant temperature, the extent of dissolution is dependent on the chemistry of the water and the amount of soluble constituents in the hardened cement paste, and the mobility of the water. If the water reservoir is small and stagnant then it is likely that the 
concentration of dissolved salts will come in equilibrium with the concrete and the dissolution process will be limited. If, however, the water is flowing, then dissolution equilibria may not be attained and leaching can then be a continuous process. Transportation of dissolved species in concrete is dependent on their migration velocity through the pore system and the flow rate of the water.

A study by Jones [2.81] on a dam constructed with stone block and mortar found that dissolution rate of the cement was about 1 $\mathrm{mm} /$ year, at a water velocity of $3 \mathrm{~m} / \mathrm{s}$. Leaching by groundwater is slow because of the low rate of groundwater movement. The average flow rate for groundwater is around $10^{-11} \mathrm{~m} / \mathrm{s}[2.77]$. An interface associated with leaching of $\mathrm{Ca}(\mathrm{OH})_{2}$ from concrete, exposed to groundwater with a flux density of $10^{-10} \mathrm{~m} / \mathrm{s}$, has been predicted to move at a rate of $1 \mathrm{~m}$ per $1.5 \times 10^{5}$ years or $6 \times 10^{-3}$ $\mathrm{mm} / \mathrm{y}[2.77]$.

The loss in concrete strength due to the leaching of $\mathrm{Ca}(\mathrm{OH})_{2}$ can be estimated by assuming that a distinct moving interface exists which seperates leached and unleached regions (the equivalent depth of concrete from which all $\mathrm{Ca}(\mathrm{OH})_{2}$ has been leached). The fractional loss in compressive strength can be estimated using $[2.82]$ :

$$
\mathrm{c}_{\text {str }}=1-\left(\mathrm{x}_{\mathrm{ca}} / \mathrm{C}_{\text {thk }}\right) 0.625
$$

where $C_{s t r}$ is fraction of original compressive strength $\mathrm{X}_{\mathrm{ca}}$ is the equivalent depth of leached concrete $(\mathrm{cm})$, and $c_{\text {thk }}$ is the thickness of structural member $(\mathrm{cm})$.

2.5.3 Possibility of Leaching Problems at Nuclear Power Facilities

Water-carrying pipes are probably the most likely components in nuclear power facilities to be degraded by leaching processes. The rate of leaching will increase with the water flow velocity and also depend on the chemistry of the water, as given by the Langelier Index. Any other concrete element subjected to flowing water, such as a cooling tower, may also be degraded by leaching. Leaching by groundwater of below-grade elements should not be a concern as long as its Langelier Index is positive. The effect of acid precipitation is not known, but is most likely to cause degradation if it can pond on a concrete surface.

\subsection{Radiation}

The effect of radiation on concrete does not appear to be unequivocally delineated. A deleterious effect of a high neutron flux on mortars was reported by Granata and Mortagnini [2.83] • 
Specimens were badly cracked when irradiated at an integrated neutron flux of $10^{20} \mathrm{n} / \mathrm{cm}^{2}$ at a temperature of $125{ }^{\circ} \mathrm{C}$. Hilsdorf, Kropp, and Koch [2.84] reviewed the knowledge of radiation damage to concrete in 1978. They noted that heat generated by radiation may cause a reduction in compressive strength, in addition to any effect of the radiation itself. Damage to concrete was thought to be caused by lattice defects in aggregates that cause a volume increase of aggregates in concrete. Such a volume increase would be of consequence if the concrete cracked or the physical properties of the concrete were significantly decreased. The studies reviewed by Hilsdorf, et al., were largely laboratory investigations. Kaplan [2.85] also reviewed and discussed the effects of nuclear radiation on the properties of concrete. He observed that prolong exposures to high nuclear fluxes can reduce the strength of concrete, with the tensile strength being most strongly affected. However, it appears that significant damage only occurs with concrete used for shielding of the higher nuclear fluxes. This concrete is non-structural and its shielding properties are not affected.

One of the few reported petrographic studies of the effect of radiation on concrete was recently performed by Buck [2.86] on concrete removed from a biological shield of a decommissioned nuclear plant in Germany. He concluded that based on petrographic examination and physical testing of concrete specimens, subjected to radiation of either around $116 \times 10^{-7} \mathrm{c} / \mathrm{kg}$ or around $4 \times 10^{-7} \mathrm{c} / \mathrm{kg}$, no radiation damage took place.

The study by Buck suggests that concrete is unaffected by the level of radiation expected in nuclear power facilities which is somewhat in contrast to the studies reviewed by Hilsdorf, et al. and by Kaplan. Obviously, further studies are needed on decommissioned facilities to quantify the effects of radiation on concrete.

\subsection{Effect of Elevated Temperature}

Several processes can elevate the temperature of concrete in nuclear power plants above ambient temperature, including absorption of radiation, failure of reactor components, and fire. Elevated temperatures can degrade concrete in several ways depending on the rate of temperature rise and the peak temperature. Internal stresses could result from differences in the thermal coefficient of expansion of the concrete consitituents, thermal gradients developed within a thick concrete element, and from restrained movement of concrete by reinforcment or by an adjacement element. Thermal cycling can be especially deleterious, depending on the temperature differential and the cycling period. Both the aggregate and hydrated cement can be degraded by elevated temperatures. In general, portland cement concretes will be durable in the approximate range of 0 
to $400^{\circ} \mathrm{C}[2.87]$. As the temperature rises above this range, the aggregate often degrades first, e.g., limestone aggregate rapidly degrades in the range of 500 to $600^{\circ} \mathrm{C}$. The dehydration of the portland cement matrix is completed at around $850{ }^{\circ} \mathrm{C}$ [2.88]. Naus reviewed [2.89] the effects of elevated temperatures on the performance and durability of concrete materials. He noted that widely accepted elevated temperature concrete design procedures do not exist. Also, he recommended that a database be developed on the effects of elevated temperatures on the performance and durability of concrete which can be used to validate and develop improved models.

\subsection{Salt Crystallization}

Dissolved soluble salts can be precipitated in the pores of porous materials as a result of water evaporation. If the pores are filled with salt crystals, further crystal growth can result in the development of internal stresses. If these stresses exceed the tensile strength of the material, cracking can occur. salt crystallization damage is usually a slow process (it is likely that only after many decades would any degradation be observed) occurring near surfaces where evaporation takes place. Recently, Sayward [2.90] suggested that salt crystallization can make a significant contribution to the deterioration of concrete and it may contribute to sulfate attack. Regarding nuclear power facilities, concrete elements most susceptible to salt damage are those where evaporation of a salt solution would be expected to take place, such as inner walls of basements, tunnels, slabs ongrade, and partly immersed columns.

\subsection{Microbiological Attack}

Microbiological attack of concrete does not appear to be common and when it occurs it is usually associated with hydrogen sulfide or sulfate producing bacteria [2.91]. For example, sulfuric acid produced by bacteria oxidizing hydrogen sulfide can attack concrete sewer pipes [2.92]. Certain bacteria are also capable of oxidizing sulfides present in the ground, such as pyrite, to sulfates in a relatively short period under aerobic conditions [2.93]. Aerobic conditions could exist during excavation of the ground for foundation construction.

In general, microbiological attack appears to be a significantly more serious problem for the organic materials of a nuclear power facility than for the concrete. However, any concrete pipes transporting sewage should be inspected for indications of hydrogen sulfide or sulfate attack. 
2.10 References

2.1. D.J. Naus, "Concrete Component Aging and Its Significance Relative to Life Extension of Nuclear Power Plants," ONRL/TM-10059, Oak Ridge National Laboratory (1986).

2.2. C.J. Hookham, "Structural Aging Assessment Methodology for Concrete Structures in Nuclear Power Plants," ORNL/NRCL/LTR-90/17, Oak Ridge National Laboratory (1991).

2.3. K. Tuutti, "Corrosion of steel in Concrete," Swedish Cement and Concrete Research Institute, Stockholm (1982).

2.4. D.A. Hausmann, "Steel Corrosion in Concrete," Materials Protection, November, pp. 19-23 (1967).

2.5. K.C. Clear, "Time-To-Corrosion of Reinforcing steel in Concrete Slabs, Volume 3: Performance After 830 Daily Salt Applications, FHWA-RD-76-70, Federal Highway Administration (April 1976).

2.6. AASHTO T259-80, "Resistance of Concrete to Chloride Ion Penetration," American Association of State Highway and Transportation Officials, Washington, D.C. (1986).

2.7. AASHTO, "Rapid Determination of Chloride Permeability of Concrete," Washington, D.C. (1990).

2.8. J.R. Clifton, L.I. Knab, E.J. Garboczi, and L.X. Xiong, "Chloride Ion Diffusion in Low-Water-To-Solid Cement Pastes," NISTIR 4549, National Institute of Standards and Technology (April 1991).

2.9. J.H. Bungey, "The Testing of Concrete structures," Chaoman Hall, Inc. (New York, 1989).

2.10. M. Schupack, "Fast Field Test for Chloride Ion," Concrete Construction, pp. 644-647 (July, 1989).

2.11. J.W. Jang and I. Iwasaki, "Visualization of Chloride Distribution in Concrete," Transportation Research Board 70th Annual Meeting, Reprint No. 910156 (January, 1991).

2.12. R.A. Livingston, L. Chang, L.S. Evans, and J.I Trombka, "The Application of the Neutron Probe to the Nondestructive Examination of Architectural and Archaeological Materials," in Materials Issues in Art and Archaeology, Materials Research Society symposium Proceedings, Vol. 123 (1988). 
2.13. R. Turriziani, "Internal Degradation of Concrete: AlkaliAggregate Reaction. Reinforcement Steel Corrosion," 8th International symposium on Chemistry of Cement, vol 1, 388-442 (Rio de Janeiro, 1986).

2.14. "Corrosion of steel in Concrete, RILEM Report, ed. Schiessl, Chapman and Hall (1988).

2.15. C.L. Page and K.W.J. Treadway, "Aspects of the Electrochemistry of steel in Concrete," Nature, Vol. 297, 109-115 (1982).

2.16. C.E. Locke, "Mechanism of Corrosion of steel in Concrete," Proceedings of Solving Rebar corrosion Problems in Concrete, Chicago NACE Convention (Sept. 1982).

2.17. J.H. Brown, "Carbonation: The Effect of Exposure and Concrete Quality: Field Survey Results from Some 400 structures," pp.249-258, in Durability of Building Materials and Components, Proceedings of Fifth International Conference (1990).

2.18. "Building Code Requirements for Reinforced Concrete," ACI 318-83, ACI Manual of Concrete Practice 1985, Part 3, American Concrete Institute.

2.19. C. Dehghanian and C.E. Locke, "Electrochemical Behavior of steel in salt Contaminated concrete: Part 1," Corrosion, Vol. 39 (8), 299-305 (1983).

2.20. D. Ho and R. Lewis, "Carbonation of Concrete and Its Prediction," Cement and Concrete Research, Vol. 17, pp. $489-504$ ( 1987 ).

2.21. R. Dhir, M. Jones, J. Munday, "A Practical Approach to studying Carbonation of Concrete," Concrete, pp. 32-34 (1985).

2.22. RILEM Recommendation CPC-18, "Measurement of Hardened Concrete Carbonation Depth," Materials and Structures, Vol. 21, No. 126, pp. 453-455 (1988).

2.23. L.J Parrott, "Assessing Carbonation in Concrete Structures," pp. 575-585, in Durability of Building Materials and Components, Proceedings of Fifth International Conference (1990).

2.24. C.N. Scott, "Corrosion Protection Properties of Portland Cement Concrete," Journal of American Water Works Association, Vol. 57 (8), 1038-1052 (1965). 
2.25. G.E. Monfore and G.J. Verbeck, "Corrosion of Prestressed Wire in Concrete," Journal of American Concrete Institute, Vol. 32 (9), 491-515 (1960).

2.26. "Corrosion of Metals in Concrete," ACI 222R-89, ACI Manual of Concrete Practice, Part 1 (1990).

2.27. R. Miller and W. Haritt, "Stray Current and Galvanic Corrosion of Reinforcing steel in Concrete," Materials Performance pp 20-27 (1976).

2.28. C. Locke, "Corrosion of steel in Portland Cement Concrete: Fundamental studies," pp 5-13, in Corrosion Effect of Stray Currents and the Techniques for Evaluating Corrosion of Rebars in Concrete, ASTM STP 906 (1986).

2.29. P. Vernon, "Stray-Current Corrosion Control in Metros," Proceeding of the Institution of Civil Engineers, Vol. 80, pp. 641-650 (1986).

2.30. H. Ansaw and D.J. Naus, "Overview of the Use of Prestressed Concrete in U.S. Nuclear Power Plants," Paper $\mathrm{H} 1 / 1$, 7th International Conference of Structural Mechanics in Reactor Technology, Chicago (August, 1983).

2.31. M. Schupack, "A Survey of the Durability Performance of Posttensioning Tendons," Journal of the American Concrete Institute, Vol. 75, pp. 501-510 (1978).

2.32. J. Feld, "Construction Failures," John Wiley and Sons, (1968).

2.33. D.J. Naus, "An Evaluation of the Effectiveness of Selected Corrosion Inhibitors for Protection of Prestressing steel in PCVVs," ORNL/TN-6479, Oak Ridge National Laboratory (1979).

2.34. J.C. Griess, "Corrosion of Steel Tendons in Concrete Pressure Vessels - Review of Recent Literature and Experimental Investigations," ORNL-NUREG-37, Oak Ridge National Laboratory (June 1978).

2.35. B.V. Ranganatham, "Corrosion and Stress Corrosion Cracking of Prestressed Concrete Structures," Transactions of the SAEST, Vol. 23, pp. 115-123 (1988).

2.36. "Standard Test Method for Half-Cell Potentials of Uncoated Reinforcing Steel in Concrete," ASTM Designation C 876. 
2.37. E. Escalante, "Effectiveness of Potential Measurements for Estimating corrosion of steel In concrete," in Corrosion of Reinforcement in Concrete, eds. C.L. Page, K.W.J. Treadway, and P.B. Bamforth, pp.281-292, Elsevier Applied Science (London, 1990).

2.38. C. Andrade, "Monitoring Techniques," in Corrosion of Steel in Concrete, Chapter 6, pp 79-95, Chapman and Hall (London, 1988).

2.39. E.Escalante, E. Whitenton, F. Qiu, "Measuring the Rate of Corrosion of Reinforcing steel in Concrete-Final Report, NBSIR 86-3456, National Bureau of Standards (October 1986).

2.40. "Guide to Durable Concrete," ACI 201.2R-77, American Concrete Institute (1977).

2.41. "Terrestrial, Materials, Health, and Visibility Effects," Volume 3 of Acidic Deposition: State of Science and Technology, National Acid Precipitation Assessment Program (Washington, D.C., 1990).

2.42. F.A. Lossing, "Sulfate Attack on Concrete Pavements in Mississippi," Highway Research Record No. 113, pp. 88-107 (1966).

2.43. J. Aldred, discussion in Proceedings of International Experience with Durability of Concrete in Marine Environment, p. 237 (University of California at Berkely, January 1989)]. 3, pp 401-406 (1983).

2.44. P.K Mehta, Mechanisms of Sulfate Attack on Portland Cement Concrete-Another Look," Cement and Concrete Research, V. 13, pp. 401-406 (1983).

2.45. C. Ouyang, "Damage Model for Sulfate Attack of Cement Mortars," Cement, Concrete, Aggregate, V. 11, No. 2, pp. 92-99 (1989).

2.46. P.K Mehta, Mechanisms of Sulfate Attack on Portland Cement Concrete-Another Look," Cement and Concrete Research, V. 13, pp. 401-406 (1983).

2.47. G.L. Kalousek, L.C. Porter, and E.J. Benton, "Concrete for Long-Term service in sulfate Environment," Cement and Concrete Research, Vol. 2 (1), 79-90 (1972).

2.48. M.D. Cohen and B. Mather, "Sulfate Attack on ConcreteResearch Needs," ACI Materials Journal, Vol. 88, No. 1, pp. $62-69$ (1991). 
2.49. ASTM Designation C 1012-88, "Standard Test Method for Length Change Hydraulic-Cement Mortars Exposed to a sulfate solution."

2.50. D. Stark, "Durability of Concrete in sulfate-Rich Soils," Research and Development Bulletin RD097.01T, Portland Cement Association (Skokie, Illinois, 1989).

2.51. N.S. Berke and M.C. Hicks, 'The Effect of Silica Fume on the sulfate Resistance of Concretes and Mortars," presented at CANMET/ACI International Workshop on the Use of Silica Fume in Concrete, Washington, D.C (April 7-9, 1991).

2.52. H. Woods, "Durability of Concrete construction," ACI Monograph No. 6, American Concrete Institute (1968).

2.53. L.S. Brown, "Some Observations on the Mechanics of AlkaliAggregate Reaction," ASTM Bulletin No. 205, p. 40 (1955).

2.54. A.L. Buck and K. Mather, "Concrete Cores from Dry Dock No. 2, Charleston Naval Shipyard, S.C.," Miscellaneous Paper No. C-69-6, U.S. Army Waterways Experimental Station, Vicksburg, Miss. (1969).

2.55. K. Mather, "Examination of Cores from Four Highway Bridges in Georgia," Miscellaneous Paper No. C-73-11, U.S. Army Waterways Experimental station, Vicksburg, Miss. (1973).

2.56. S. Diamond, "ASR-Another Look at Mechanisms," in AlkaliAggregate Reaction: 8th International Conference, pp. 8894, Elsevier Applied Science (1989).

2.57. G.M. Idorn, "Alkali-Silica Reactions in Retrospect and Prospect," in Alkali-Aggregate Reaction: 8th International Conference, pp. 1-8, Elsevier Applied Science (1989).

2.58. R.N. Swamy, "Structural Implications of Alkali silica Reaction," in Alkali-Aggregate Reaction: 8th International Conference, pp. 683-689, Elsevier Applied Science (1989).

2.59. D.K Doran and J.F.A. Moore, "Appraisal of the structural Effects of Alkali-Silica Reaction," in Alkali-Aggregate Reaction: 8th International Conference, pp. 677-682, Elvesier Applied Science (1989).

2.60. "Standard Practice for Petrographic Examination of Aggregates for Concrete," ASTM Designation: C 295

2.61. "Standard Test Method for Potential Alkali-Aggregate Reactivity of Cement-Aggregate Combinations," ASTM Designation C 227 . 
2.62. "Standard Test Method for Potential Reactivity of Aggregates (Chemical Method)," ASTM C 289.

2.63. J.R. Clifton and L.I. Knab, "Selection of Siliceous Aggregate for Concrete," NISTIR 4327, National Institute of Standards and Technology (1990).

2.64. ASTM P 214 "Test Method for Accelerated Deleterious Expansion of Mortar Bars Due to Alkali-Silica Reaction."

2.65. R.E. Oberholster and G.S. Davies, "An Accelerated Method for Testing The Potential Alkali Reactivity of Silicious Aggregates," Cement and Concrete Research, Vol. 16, pp. 181-189 (1986).

2.66. C.A. Rogers, "Evaluation of the Potential for Expansion and Cracking of concrete caused by the Alkali-Carbonate Reaction," Cement, Concrete, and Aggregates, Vol. 8, pp. 13-23 (1986).

2.67. "Standard Test Method for Potential Alkali Reactivity of Carbonate Rocks for Concrete Aggregates (Rock Cylinder Method)," ASTM Designation C 586.

2.68. K. Natesaiyer and K.C Hover, "Insitu Identification of ASR Products in Concrete," Cement and Concrete Research, Vol. 18, pp. 455-463 (1988).

2.69. K. Natesaiyer and K.C. Hover, "Some Field strategies of the New Insitu Method for Identification of Alkali Silica Reaction Products in concrete," cement and concrete Research, Vol. 19, pp. 770-778 (1989).

2.70. "Handbook for the Identification of Alkali-Silica Reactivity in Highway Structures," SHRP-C/FR-91-101, Strategic Highway Research Program (Washington, D.C., 1991).

2.71. M. Neville, "Properties of Concrete," (3rd ed.), Pitman Publishing Ltd. (London, 1981).

2.72. G. Fagerlund, "Prediction of the Service Life of Concrete Exposed to Frost Action," in Studies on concrete Technology, Swedish cement and Concrete Research Institute (1978).

2.73. W.A. Cordon, "Freezing and Thawing of Concrete--Mechanisms and Control," ACI Monograph No.3, American Concrete Institute (1966).

2.74. "Standard Test Method for Resistance of Concrete to Rapid Freezing and Thawing," ASTM Designation: C 666. 
2.75. R. Shuman, V.V. Rogers, and R.A. Shaw, "The Barrier Code for Predicting Long-Term Concrete Performance," Waste Management 89, University of Arizona (1989).

2.76. "Standard Test Method for Critical Dilation of Concrete specimens Subjected to Freezing," ASTM Designation C 671 .

2.77. A. Atkinson, "The Time Dependence of pH within a Repository for Radioactive Waste Disposal," Report AERE R 1177, Materials Development Division, Harwell Laboratory, Oxfordshire (1985).

2.78. B.P. Hughes and J.E. Guest, "Limestone and Siliceous Aggregate Concretes subjected to Suphuric Acid Attack," Magaazine of Concrete Research, Vol. 30, No. 102, pp. 11-18 (1978).

2.79. W.G. Hime, B. Erlin, and R.R. Mcormond, "Concrete Deterioration Through Leaching with soil Purified water," Cement, Concrete, and Aggregates, Vol. 8 (1), 50-51 $(1986)$.

2.80. W.F. Langelier, Journal of the American Water Works Association, Vol. 23, 1500 (1936).

2.81. A.N. Jones, "Preliminary Field Studies of Rates of Dissolution of Hydrated Cement, " Magazine of Concrete Research, Vol. 41, No. 148, pp. 155-162 (1989).

2.82. A. Atkinson and J.A. Hearne, "An Assessment of the LongTerm Durability of Concrete in Radioactive Wasste Repositories," Report AERE - R 11465, Materials Development Division, Harwell Laboratory, oxfordshire $(1984)$.

2.83. S. Granata and A. Montagnini, "Studies of Concrete under Irradiation," in Concrete for Nuclear Reactors, ACI SP-34, pp. 1163-1172 (American Concrete Institute, 1972).

2.84. H.K Hilsdorf, J. Kropp, and H.J. Koch, "The Effect of Nuclear Radiation on the Mechanical Properties of Concrete," in Douglas McHenery International Symposium on Concrete and Concrete Structures, ACI SP-55, pp. 223-251 (American Concrete Institute, 1978).

2.85. M.F. Kaplan, "Concrete Radiation Shielding," Longman Scientific and Technical (England, 1989).

2.86. A.D. Buck, "Characterization of Radioactive concrete by Petrographic and Physical Means," ACI Materials Journal, pp. 55-58 (January-February 1988). 
2.87. D.F. Orchard, "Concrete Technology," Vol. 1, 4th ed., Applied Science Publishers LTD (London, 1979).

2.88. T.Z. Harmathy, "Thermal Properties of Concrete at Elevated Temperatures," ASTM Journal of Materials, Vol. 5, pp. 4774 (1970).

2.89. D.J. Naus, "A Review of the Effects of Elevated Temperataure on Concrete Materials and Components with Particular Reference to the Modular High-Temperature GasCooled Reactor (MRTGR)," ORNL/NRC/LTR-88/2, U.S. Nuclear Regulatory Commission (Marach 1988).

2.90 J.M. Sayward, "Salt Action on Concrete," Special Report 84-25, U.S. Army Cold Regions Research and Engineering Laboratory, Hanover, NH (1984).

2.91. I. Biczok, "Concrete corrosion and concrete Protection," Chemical Publishing Co., Inc., N.Y. (1967).

2.92. C.E. Kulpa and C.J. Baker, "Involvement of Sulfuroxidizing Bacteria in Concrete Deterioration," in Paul Klieger Symposium on Performance of Concrete, ACI SP-122, pp. 313-322 (American Concrete Institute, I990). 
3. REVIEW OF METHODS FOR PREDICTING THE SERVICE LIFE OF NEW CONCRETE

\subsection{Methods for Predicting Life of New Concrete}

Methods which have been used for predicting the service lives of construction materials have been reviewed by clifton [3.1]. They include $i)$ estimates based on experience, $i i$ ) deductions from performance of similar materials, iii) accelerated testing, iv) applications of reliability and stochastic concepts, and v) mathematical modeling based on the chemistry and physics of degradation processes. Although these approaches are discussed separately, they often are used in combination.

\subsubsection{Estimates Based on Experience}

A common method of making semi-quantitative predictions of the service life of concrete is expert judgement based on the accumulated knowledge from laboratory and field testing, and experience. This body of accumulated knowledge contains both empirical knowledge and heuristics; collectively, these provide the largest contriburion to the basis of standards for concrete. It is assumed that, if concrete is made following the standard guidelines and practices, it will have the required life. This approach gives an "assumed service life" prediction. The concrete may perform adequately for its design life, especially if the design life is fairly short and the service conditions are not too severe. This approach breaks down when it becomes necessary to predict the service life of concrete which is required to be durable for a time which exceeds our experience with concrete, when new environments are encountered, or when new concrete materials are to be used. For example, Fagerlund [3.2] analyzed several situations where this approach was used and concluded that experience or qualitative assessments of durability do not form a reliable basis for service life predictions.

\subsubsection{Predictions Based on Comparison of Performance}

The comparative approach has not been commonly used for concrete but, with a growing population of aging concrete structures, we can expect that its use will increase. In this approach, it is assumed that, if a concrete has been durable for a certain time, a similar concrete exposed to a similar environment will have the same life. A problem with this approach is each concrete structure is unique because of variability in materials, geometry, and construction practices. Also, over the years, the properties of concrete materials have changed. For example, portland cements are ground finer today than they were 40 years ago, to achieve increased early age strength. The smaller particle size may be detrimental to the durability of concrete 
[3.3]. In contrast, advances in chemical and mineral admixtures have led to the development of concrete with potentially improved performance and durability. Another problem with the comparison approach is differences in the microclimates to which concrete structures are exposed which may have unanticipated effects on the concrete durability. Therefore, comparisons between the durabilities of old and new concretes are not straightforward.

\subsubsection{Accelerated Testing}

\subsubsection{Approach}

Most durability tests for concrete involve the use of elevated stresses (concentration of reactants, temperature, humidity, etc.) to accelerate degradation. Accelerated testing programs, if properly designed, performed, and interpreted, should provide a sound basis for predicting the performance and service life of concrete. Use of accelerated testing for predicting the service life of several types of building materials was discussed by Frohnsdorff et al. [3.4]. An important requirement for using accelerated testing is that the degradation mechanism in the accelerated test should be the same as that responsible for the in-service deterioration. If the degradation proceeds at a proportional rate by the same mechanism in both accelerated aging and long-term in-service tests, an acceleration factor, $k$, can be obtained, from:

$$
K=R_{A T} / R_{L T}
$$

where $R_{A T}$ is the rate of change in accelerated tests, and $R_{L T}$ is the rate of change in long-term in-service testing. If, as is usually the case, the relationship between the rates is nonlinear, then mathematical modeling of the degradation mechanism is recommended to establish the relationship.

\subsubsection{Application}

An example of the application of accelerated testing to service life predictions is provided by Vesikari [3.5]. He related the "Iifetime" of a specimen in an accelerated test, $t$ ", to the service life of a structure, $t_{1}$, by:

$$
t_{1}=k t^{\prime}
$$

where $\mathrm{k}$ is a constant, then applied this approach to frost resistance testing of concrete, as follows. In an accelerated frost test the lifetime of a specimen is expressed in terms of the number of freezing and thawing cycles. Assuming that the number of freezing and thawing cycles to which a structure is subjected annually to be constant, he showed that the service life of the structure can be evaluated by: 


$$
t_{1}=k_{e} N
$$

where $k_{e}$ is a coefficient related to environmental conditions and $\mathrm{N}$ is the number of freezing and thawing cycles causing a specified amount of damage to a laboratory specimen.

This approach was further developed to predict the life of concrete exposed to the combined effect of frost and salt scaling action. In this case, the service life is given by:

$$
t_{1}=k_{e} P
$$

where $P$ is the frost resistance index. $P$ is obtained by the DBV Deutsche Beton Verein) freeze-salt test [3.5]. Values of the environmental coefficient, $k_{e}$, were based on field investigations in which the correlation between the degree of damage of the structure, age of the structure, and the frost resistance of the structure were analyzed.

The following study illustrates the application of an accelerated test method for estimating the service lives of concretes exposed to sulfate salts. In this study the US Bureau of Reclamation combined the results of accelerated tests and long-term tests [3.6]. In the long-term tests, concrete specimens were continuously immersed in a $2.1 \% \mathrm{Na}_{2} \mathrm{SO}_{4}$ (sodium sulfate) solution until failure (defined as an expansion of $0.5 \%$ ) occurred or until the investigation was completed. The age of specimens at the completion of the continuous-immersion study was between 18 to 24 years. Companion specimens were subjected to an accelerated test in which the specimens were exposed to repeated cycles of immersion in a $2.1 \% \mathrm{Na}_{2} \mathrm{SO}_{4}$ solution for 16 hours and forced air drying at $54^{\circ} \mathrm{C}\left(130^{\circ} \mathrm{F}\right)$ for 8 hours. From a comparison of the times for specimens to reach an expansion of $0.5 \%$ in the accelerated test and the continuous immersion test, it was estimated that 1 year of accelerated testing equalled 8 years of continuous immersion. In this case, equation 3.1 becomes:

$$
\mathrm{K}=8=\mathrm{R}_{\mathrm{AT}} / \mathrm{R}_{\mathrm{LT}}
$$

where $R_{A T}$ is the rate of change in the accelerated test, and $R_{L T}$ is the rate of change in the long-term continuous immersion test. A $2.1 \%$ solution of $\mathrm{Na}_{2} \mathrm{SO}_{4}$ is a severe environment and if concrete was exposed to a lower concentration of sulfate the life expectancy would be expected to be longer. This method could be used for predicting the service life of concretes continuously immersed in a different concentration of sulfate ions, if the acceleration factor of $1: 8$, obtained using the $2.1 \%$ sulfate solution, holds for other sulfate concentrations. In reality, it is likely that the degradation mechanisms associated with the accelerated tests were not the same as those occurring in the 
continuous immersion tests. During the continuous immersion, sulfate ions would migrate into the concrete by diffusion alone while, in the immersion and drying tests, the sulfate would likely be transported by convection, diffusion, and capillary forces. Also, in the immersion and drying test, the concentration of sulfate ions would likely be higher near the surfaces of the test specimens than in the immersion solution, because the evaporation of the solute would tend to draw the sodium sulfate near the specimens surfaces, where it could precipitate. While the severity of sulfate attack increases with concentration, the reaction mechanism also changes. For example, with low concentrations of sulfate (less than $830 \mathrm{mg} / \mathrm{l}$ ), ettringite formation is considered [3.7] to be the main cause of deterioration while, at higher concentrations, gypsum formation tends to become the dominant deterioration process. A $2.1 \%$ sodium sulfate solution gives a concentration of $21000 \mathrm{mg} / \mathrm{l}$, which means that it is likely that both ettringite and gypsum formed in the test.

\subsubsection{Stochastic Methods}

The use of stochastic concepts in making service life predictions of construction materials has been explored by several researchers, including sentler [3.8] and Martin [3.9]. Service life models using stochastic methods are based on the premise that service lives cannot be precisely predicted [3.10]. A large number of factors affect the service life of concrete and their interactions are not well known. These factors include the extent of adherence to design specifications, variability in the properties of hardened concrete, randomness of the in-service environment, and materials response to microclimates. Two stochastic approaches are the reliability method and the combination of statistical and deterministic models.

\subsubsection{Reliability Method}

The reliability method combines the principles of accelerated degradation testing with probabilistic concepts in predicting service life. This method has been discussed by Martin [3.9] and applied to coatings [3.11] and roofing materials [3.12]. Application of the method is described below by considering concrete subjected to a hypothetical laboratory durability test.

As is typical of any engineering material, supposedly identical concrete specimens exposed to the same conditions will have a broad distribution of times to failure. The reliability method takes into account the time-to-failure distributions. By elevating the stresses which have the major effect on accelerating failure, probability of failure data can be obtained as shown in Fig 3.1. These plots are based on the premise that time to failure data can be described by a Weibull distribution [3.9]. Testing of multiple specimens, at each stress level, is 


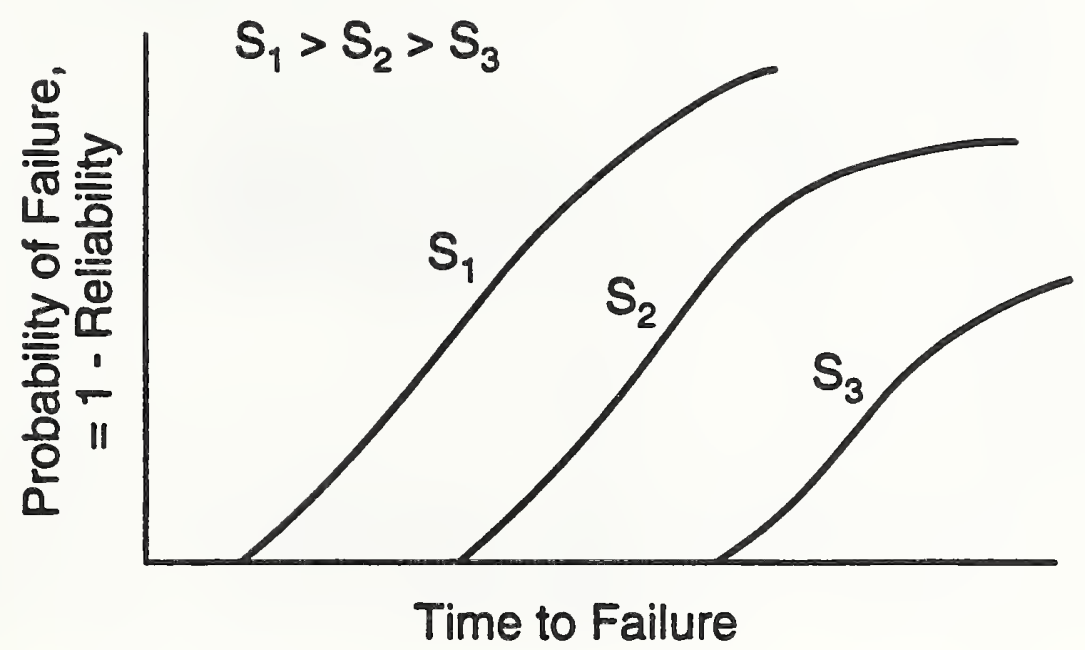

Figure 3.1 Probability of Failure at Different Stress Levels [3.9]. 


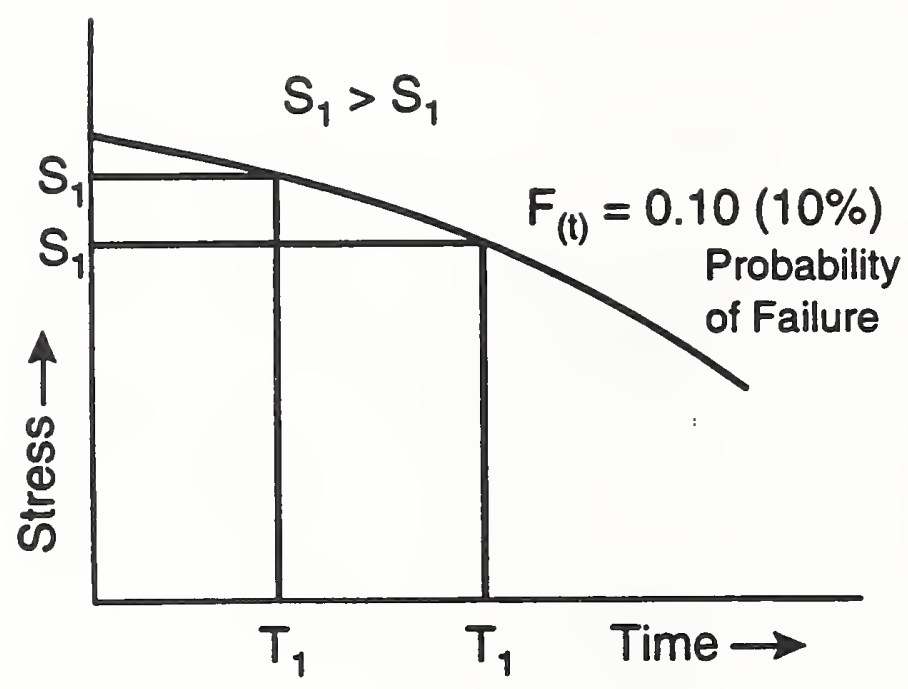

Figure 3.2 Probability-of-Failure Stress Time-to-Failure (P-S-T) Diagram Showing the $10 \%$ Probability of Failure Curve [3.9]. 
required to obtain the distributions. If the failure rate increases as the stress level increases, the life distribution at in-service stresses can be related to the life distribution at elevated stress by the time transformation function, $p_{i}(t)$, which is expressed as [3.9]:

$$
F_{i}(t)=F_{o}\left(p_{i}(t)\right)
$$

where $t$ is time, $F_{i}(t)$ is the life distribution at the i'th elevated stress level, and $F_{o}(t)$ is the life distribution at the in-service stress level. From equation 3.6, a probability-offailure stress time-to-failure (P-S-T) diagram can be prepared as shown in Fig 3.2. The curves in a P-S-T diagram, e.g., the $F(t)$ $=0.10$ curve, are iso-probability lines. The iso-probability lines give, for each stress level, the time at which a given fraction of a group of specimens can be expected to have failed. The P-S-T diagram gives a basis for predicting the service life of concrete if the in-service conditions are in the range covered by the diagram and are not anticipated to change significantly.

The time transformation function approach is applicable if i) the deterioration mechanism under all tested stress levels is the same as that under in-service conditions, ii) deterioration begins at the instant of stress application, and iii) deterioration is an irreversible cumulative process.

\subsubsection{Combination of Statistical and Deterministic Models}

Often statistical models are combined with deterministic models. For example, siemes et al. [3.13] predict the mean service life of buildings by using mean values for the parameters in deterministic models. The standard deviation of the service life was calculated using the expression:

$$
\sigma^{2}\left(t_{1}\right)=\sum_{j=1}^{n} \quad\left\{\frac{\partial t_{1}}{\partial x_{j}} \cdot \sigma\left(x_{j}\right)\right\}^{2}
$$

where $\sigma\left(t_{1}\right)$ is the standard deviation of service life, $\sigma\left(x_{j}\right)$ the standard deviation of the variable $x_{j}$,

$\frac{\partial t_{1}}{\partial x}$ the partial derivation of $t_{1}$ with respect

$\partial \mathrm{x}_{j}$ to $\mathrm{x}_{j}$, and

$n$ is the number of variables.

The partial derivatives $\partial t_{1} / \partial x_{j}$ are calculated for the mean values of the stochastic variables. In this approach, it is assumed that the $x_{j}$-variables are statistically independent. 
Siemes, et al recommended log-normal distributions for representing the service life [3.13]. Sentler [3.8] developed a model for carbonation which demonstrates the application of the stochastic method. The depth of carbonation ( $x$ ) in concrete was represented by the following form of Fick's diffusion law:

$$
x^{2}=(2 D / a) d p \cdot t
$$

where $D$ is the diffusion coefficient, $d p$ is the partial pressure difference for $\mathrm{CO}_{2}$, and $t$ is the time. When represented as a stochastic process the depth of carbonation is expressed by:

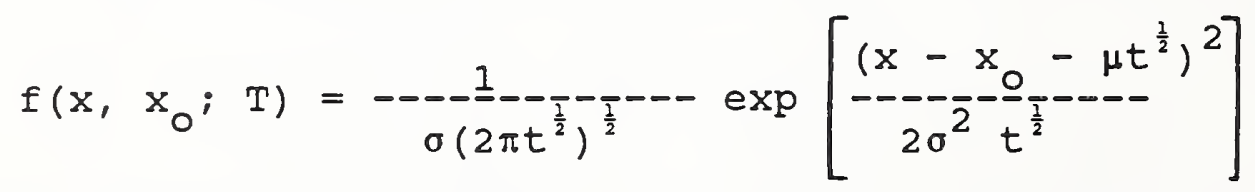

which is a normal density function, $f$, with mean $x_{0}+\mu t^{1 / 2}$ and variance $\sigma^{2} t^{\frac{1}{2}}$. The initial value of $x, x_{0}$, is used to account for a faster carbonation taking place in the concrete surface layer. Equation 3.9 gives the same mean rate of carbonation as equation 3.8 , but with a variability in the depth of carbonation determined by a normal density function. The model was solved for a case where the cover over concrete was $25 \mathrm{~mm}$, with a waterto-cement (w/c) ratio of 0.5 , and had carbonated for 50 years. An initial fast carbonation was assumed which corresponded to $x_{0}$ $=3 \mathrm{~mm}$. The statistical parameters were taken from a field study of the relationship between $\mathrm{w} / \mathrm{C}$ ratio and depth of carbonation in $\mathrm{mm} / \mathrm{y}^{1 / 2}$. About $16 \%$ of the data was more than one standard deviation from the mean value, indicating a normally distribution. A probability of $2.3 \times 10^{-4}$ for carbonation at $25 \mathrm{~mm}$ after 50 years was obtained. If the $\mathrm{w} / \mathrm{c}$ ratio was increased to 0.6 the probability became $3.3 \times 10^{-2}$.

\subsection{Mathematical Modeling}

Several models have been developed for predicting the service life of concrete subjected to degradation processes such as corrosion, sulfate attack, leaching, and frost damage [3.14]. The feasibility of using mathematical models for predicting service lives of concrete has been discussed by Pommersheim and clifton [3.15]. Walton, et al. [3.16], reviewed models for predicting the service life of concrete used in constructing underground vaults for the disposal of low-level nuclear waste. They reported on models for sulfate attack, corrosion of reinforcement, leaching, and frost attack. Many of the degradation processes of concrete, excluding those caused by excessive mechanical loading, are associated with the intrusion of concrete by water, ions or gases. For such processes, mathematical models for predicting service life can be developed by considering $i)$ the rate of penetration of aggressive media 
into concrete, and $i$ ) the rate of chemical reactions and physical processes. Mathematical models of degradation processes controlled by the ingress of water, salts, and gases into concrete by convection and diffusion have been described by Pommersheim and Clifton [3.17]. Service life models for the degradation processes which are considered to be the most likely to have a serious effect on the condition of concrete of nuclear power plants are analyzed in terms of their assumptions, mathematical formulation, and application in the following. Because service life models have not been reported for alkaliaggregate reactions, an approach for developing an appropriate model is discussed. Models developed for frost attack and leaching are also described. Service life models have not been found for degradation caused by radiation, salt crystallization, and microbiological attack.

\subsubsection{Corrosion Models}

\subsubsection{Empirical Models by stratfull and clear}

Stratfull [3.18, 3.19] developed an empirical model for the corrosion of reinforced concrete exposed to salt water, based on field test results from corrosion studies of bridges in the state of California. The following model resulted from regression fitting of the corrosion data:

$$
R t=\left(10^{0.0442 C_{C}} 0.717 \mathrm{Si}^{1.22} 1011\right) / \mathrm{K}^{0.42} \mathrm{Wm}^{1.17}
$$

where Rt is years to failure,

$C$ is the sacks of cement per cubic yard of concrete

$\mathrm{Si}$ is the depth of steel below the concrete surface in inches,

$\mathrm{K}$ is the chloride concentration in seawater, in ppm, and $\mathrm{Wm}$ is the mixing water in percent of concrete volume.

In this model, failure occurs when concrete has degraded to a state which requires repair or replacement.

Clear [3.20] modified the model based on corrosion data obtained from the daily application of a $3 \%$ solution of sodium chloride to reinforced concrete slabs. After 830 applications of the sodium chloride solution, the following model was obtained by regression fitting of the corrosion data:

$$
R t=\left(129 \mathrm{Si}^{1.22}\right) / \mathrm{K}^{0.42} \mathrm{w} / \mathrm{C}
$$

where $\mathrm{w} / \mathrm{c}$ is the water-to-cement ratio by weight.

Both models indicated that the $\mathrm{w} / \mathrm{c}$ of concrete was the main factor in the mix design of concrete controlling its resistance to corrosion induced by chlorides. The models, however, do not 
predict the time of impending corrosion or the rate of degradation by active corrosion of reinforcing steel.

\subsubsection{Empirical Models Reported by Vesikari}

Vesikari described [3.10] mechanistic models empirically fitted to data from field and laboratory studies. Corrosion induced by chloride ions and by carbonation are dealt with by the models. Both the initiation and propagation periods are modelled. These models are useful in identifying the factors controlling the service life of reinforced concrete when corrosion is the major degradation process. They are easily solved using empirically derived coefficients for the quality of concrete, environments, and intensity of active corrosion. Effects of different types of cements, extent of carbonation, and compressive strength of concrete on corrosion are considered by the coefficient for the quality of concrete. The reliability of these models when projected to other concretes and environments needs to be determined before they should be widely used.

\subsubsection{Model by Tuutti}

Tuutti [3.21] has developed a model for predicting the service life of reinforcing steel which will be outlined in some detail because most corrosion models follow the same broad approach development. His model is based on the corrosion sequence schematically shown in Fig. 3.3. In this model, corrosion starts after the end of an initiation period of no corrosion, followed by a propagation period of active corrosion. The corrosion process is initiated by the diffusion of chloride ions to the depth of the reinforcing steel or by carbonation reducing the $\mathrm{pH}$ of the pore liquid in contact with the steel, or by the combination of chloride ions and carbonation.

In the following, only the effect of chloride ions on the initiation period will be considered. The length of the initiation period is largely controlled by the rate of diffusion of the chloride ions in the concrete and by the threshold concentration for the process. Because chloride ions may react with the tricalcium aluminate of portland cement the concentration has two components; concentration of bound chloride ions $\left(c_{b}\right)$ and concentration of free ions $\left(c_{f}\right)$, related by the constant $\mathrm{R}$ :

$$
c_{b}=R \cdot c_{f}
$$

The diffusion equation, in one dimension, can be expressed as:

$$
\partial c_{f} / \partial t=[D /(R+1)] \cdot \partial^{2} c_{f} / \partial x^{2}
$$




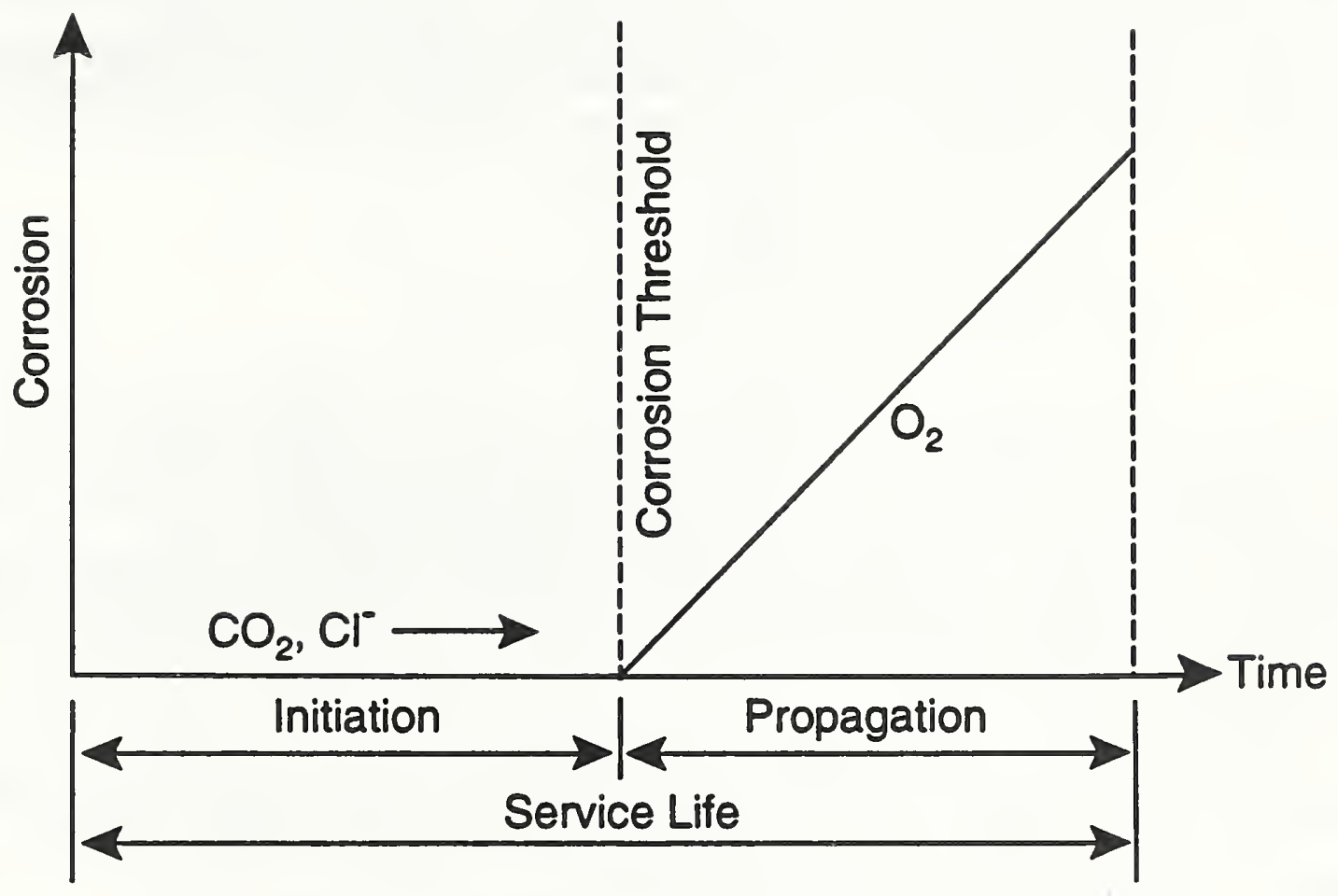

Figure 3.3 Schematic of Conceptual Model of Corrosion of Steel Reinforcement in Concrete [3.21]. 
where $D$ is the diffusion coefficient, $x$ is distance, and $t$ is time. In this equation, the term $D /(R+1)=D_{\text {eff }}$ is the effective diffusion coefficient.

The corrosion rate in the propagation period is controlled by the rate of oxygen diffusion to the cathode, resistivity of the pore solution, and temperature. At $10^{\circ} \mathrm{C}$, the propagation time for reinforced concrete structures, such as bridges, has been estimated to be 5 to 10 years for corrosion caused by chlorides and 15 to 20 years if caused by carbonation [3.21]. The diffusion resistance to oxygen is determined by the water saturation of the concrete cover and by the cross-section of pores not filled with water, which are dependent on the concrete's porosity, pore size distribution, inter-connectiveness of pores, and ambient relative humidity. The combined mass transfer coefficient, $K_{t}$, for oxygen through both unfilled and water saturated pores is given by:

$$
\begin{gathered}
K_{t}=K_{a i r}+\left(K_{H 2 O}\right) / m \\
=\left(8 \cdot 10^{-7} / X_{\text {air }}\right)+10^{-7} / 4 \cdot 10^{4} \cdot X_{H 20} \cdot
\end{gathered}
$$

where $\mathrm{m}$ is a temperature dependent constant and $\mathrm{X}$ is the distance (in meters) in either a air or water filled pore or pore network. The migration of oxygen through saturated concrete is a significantly slower process than through partially water filled concrete and thus can become the rate controlling process. The effects of water in the pores on corrosion is demonstrated by the observation that corrosion at a relative humidity of $100 \%$ is negligible [3.21].

In using the model for predicting service lives, the recommended procedure by Tuutti [3.21] is given by the following steps:

Step 1. Compile the relevant material, structural, and environmental data.

Step 2. Calculate initiation time, based on experimental data for the diffusion rates and threshold concentration of corrosive substances.

Step 3. Calculate the corrosion rate in the propagation stage.

Step 4. Determine the amount of steel corrosion required to cause failure.

Tuutti [3.21] has provided values for many of the model parameters which can be used in estimating the service life of reinforced concrete exposed to corrosive environments. Also, he has given recommendations on methods for obtaining values for the 
other parameters. The model appears to provide a means for making semi-quantitative predictions of the minimum service life of concrete structures. While the predictions seem reasonable, further studies are needed to compare them with field test data.

clifton, et al. [3.22], used the concepts of Tuutti's model to predict the effects of the chloride ion diffusion coefficient and the depth of cover on the length of the initiation period. The initiation period is determined for the reinforced concrete element shown in Fig. 3.4 as follows. $\mathrm{C}_{\mathrm{AO}}$ is the concentration of chloride ions at the outside surface of the concrete and $c_{i}$ is the concentration at the depth of the reinforcement, which is assumed to be initially 0 . The initiation period is completed when $c_{i}=c_{t}$, the threshold concentration. The time for $c_{i}=c_{t}$ can be calculated using Fick's second law of diffusion [3.23]:

$$
\frac{\partial C}{\partial t}=D \frac{\partial^{2} C}{\partial Z^{2}}
$$

where $\mathrm{C}$ is the chloride ion concentration

$t$ is the time

$\mathrm{Z}$ is the distance

$D$ is the diffusion coefficient.

The general solution to equation (3.16) for the concrete element in Fig. 3.6 is:

$$
\frac{C}{C_{0}}(z, t)=\sum_{n=0}^{\infty}(-1)^{n}\left[\operatorname{erf}\left\{\frac{(2 n+1)-y}{2 \sqrt{r}}\right\}+\operatorname{erf}\left\{\frac{(2 n+1)+y)}{2 \sqrt{r}}\right\}\right]
$$

where erf is the error function [3.24],

$$
\begin{aligned}
& y=(L-x) / L, \text { and } \\
& r=D t / L 2 . \\
& x=\text { depth of cover } \\
& L=\text { thickness of concrete element }
\end{aligned}
$$

However, in the present case, only the $\mathrm{n}=0$ term of equation (3.17) needs to be considered (higher order terms have insignificant contributions to the summation), reducing to:

$$
\frac{C}{C_{0}}=\operatorname{erf} \frac{(1-y)}{2 \sqrt{r}}
$$


where $1-y=x / L$.

The model is solved for a concrete element with the following properties: $D=5 \times 10^{-13} \mathrm{~m}^{2} / \mathrm{s} ; \mathrm{x}=50 \mathrm{~mm} ; \mathrm{L}=300 \mathrm{~mm} ;$ and $\mathrm{C}_{i}=0$ at $t=0$. The threshold concentration of chloride ions, $c_{t}$, is taken to be $0.4 \%$ (based on weight of cement). At its surface, the concrete is exposed to an concentration of chloride ions, $C_{0}$, equivalent to $0.7 \%$, based on the weight of cement. The end of the initiation period is predicted to be 23 years, which will be followed by rapid corrosion. In the above calculation, the value of $\mathrm{D}$ is considered to be indicative of high quality concrete.

\subsubsection{Model for Corrosion by Sea Water}

A model somewhat similar to that of Tuutti [3.21] was developed by Bazant [3.25, 3.26] for corrosion of reinforced concrete exposed to sea water. This model is comprehensive and mathematically describes the following processes:

(1) diffusion of oxygen and chloride ions in concrete pore water,

(2) depassivation of steel due to chloride ions,

(3) effects of oxygen and iron (II) hydroxide on cathodic and anodic potentials and their polarizations,

(4) flow of electrical current through the electrolyte in pores,

(5) mass sinks for oxygen, iron (II) hydroxide, and hydrated red rust, and

(6) rust production rates based on reaction kinetics.

The complete equation system is extremely complicated and its complete solution has not been accomplished. Nevertheless, the model is based on a logical approach for developing, from theory, a method for calculating the service life of reinforced concrete. Based on several simplifying assumptions, the use of the model to predict the service life of concrete structures in sea water has been demonstrated. For example, it predicts that a deeply submerged reinforced concrete structure could have a service life (considering only corrosion) of some 15,000 years. Subramanian and wheat [3.27] reported on the results of a one-dimensional solution to Bazant's model which predicts when corrosion will start, i.e., the end of the initiation period. The solution is similar to that obtained from Tuutti's model.

\subsubsection{Corrosion Induced by Carbonation}

The depth of carbonation in concrete has been shown to follow a classical diffusion model of the form [3.28]:

$$
x=\left[2 D_{c}\left(c_{1}-c_{2}\right) t\right]^{1 / 2}
$$






Figure 3.4 Schematic of Reinforced Concrete Element and Chloride Ion Diffusion. 
where $\mathrm{x}$ is the depth of carbonation

$\mathrm{D}_{\mathrm{c}}$ is the diffusion coefficient for $\mathrm{CO}_{2}$ of concrete of a given composition and moisture condition,

$\mathrm{c}_{1}-\mathrm{c}_{2}$ is the concentration difference of $\mathrm{CO}_{2}$ between air

$t$ is time. and the carbonation front, and

At a given moisture content $D_{c}$ will be constant with time. With changing relative humidities, however, $D_{c}$ will change. Schiessel [3.28] suggested a modified model which considers the dependence of $\mathrm{D}_{\mathrm{C}}$ with the change of moisture content of concrete as the carbonation interface moves inward in concrete. $D_{C}$ is replaced by the combination of $D_{B, A}$, which is the diffusion coefficient at an age of about 90 days, and $f$, a factor which describes the decrease of $D_{B, A}$ with depth.

Another model was developed by Rijnen [3.28] which has the same form as equation (3.19) if the concrete is dry. However, if the concrete is subjected to periods of wetting and drying the model predicts that when the concrete is wet, the carbonation depth will go to a limit, $\mathrm{x}_{1 \mathrm{im}}$. The limit will be reached when:

$$
t_{n}-\left[\left(x_{n}-1\right) / B\right]^{2}=0
$$

where $t_{n}$ is the duration of the $n$ 'th drying period,

$\mathrm{x}_{\mathrm{n}}$ is the carbonation depth after the n'th drying period, and

$B$ is given by:

$$
B=\left[\left(2 D_{C}\left(C_{3}-C_{4}\right)\right) / b\right]^{1 / 2}
$$

In equation (3.21), $c_{3}-c_{4}$ is the moisture difference between the air and that at the evaporation depth, and $b$ is the amount of water evaporated from the concrete in reaching $x_{n}$. Thus

$$
\mathrm{x}_{1 \mathrm{im}}=\mathrm{B}\left(t_{\mathrm{n}}\right)^{1 / 2}
$$

If the concrete does not dry, $t_{n}=0$ and $x=0$. Therefore, depending on the moisture condition of concrete the rate of carbonation will have a time dependence $t^{\mathrm{n}}$, with $\mathrm{n}$ ranging between $1 / 2$ for dry concrete, and approaching 0 for saturated concrete. The effect of moisture conditions on the rate of carbonation of concrete is shown in Fig. 3.5 .

Assuming that interior concrete in nuclear power plants is unsaturated, it is recommended that equation (3.20) be used for interior concrete. This will predict the maximum depth of carbonation in the faces of interior concrete based on the existing depth of carbonation. The model by Rijnen [3.28] would 
be applicable to predicting the depth of carbonation in the exterior faces of concrete.

3.2.1.6 Modeling Stress Corrosion Cracking (SCC) of Prestressed Steel

The SCC of prestressing steel was modeled by Wu and Clifton $[3.29,3.30]$ based on a thermodynamic approach. With further development the model could be used to predict the SCC behavior of prestressing steel in concrete structures. Simplified general equations were used to predict the rate at the anode and cathode. SCC was modeled by assuming that it followed either an

intercrystalline or a transcrystalline path and expressing the fracture energy, $W$, by:

$$
w=w_{d}+w_{s}+w_{e}+w_{c}
$$

where $\mathrm{w}_{\mathrm{d}}$ : the energy related to the stress field of the dislocation,

$\mathrm{W}_{\mathrm{S}}$ : surface energy of new cracks in the metal,

$\mathrm{W}_{\mathrm{e}}$ : elastic energy of the crack, and

$\mathrm{w}_{\mathrm{c}}$ : work done in increasing the volume by opening up the crack.

A modified form of Gibb's equation was proposed to consider the chemical potentials at the grain boundaries:

$$
d \tau+\Sigma \mu_{i} d C_{i}+d E_{d}=0
$$

where $\tau$ is the free surface energy and $\mu_{i}$ represents the chemical potentials for the species considered, and $c_{i}$ represents the surface concentrations. The variable $d_{E_{d}}$ is introduced to compensate for discrepancies between the theoretical predicted and the actual SCC behaviors. The value of $\mathrm{dE}_{\mathrm{d}}$ should be obtained directly from the experimental data.

Linking equation (3.24) with the general equations for the kinetics at the cathode and anode should permit the mathematical description of the complete SCC process.

\subsubsection{Sulfate Attack}

\subsubsection{Empirical Model}

An empirical model for predicting the service life of concrete exposed to groundwater containing sulfate salts was developed by Atkinson and Hearne [3.31] based on the studies by Harrison and Teychenne [3.32]. In the laboratory, concrete specimens were immersed in a $0.19 \mathrm{M}$ sulfate solution (a mixture of alkali and magnesium sulfates) for up to 5 years. The accelerated laboratory 




Figure 3.5 Effect of Mmicro-Eenvironment in a Ddamp climate on Rate of Carbonation of Concrete [3.28]. 
tests resulted in a visible deterioration zone, $x_{S}$, and the following empirical equation was developed:

$$
\mathrm{X}_{\mathrm{S}}(\mathrm{cm})=0.55 \mathrm{CA}(\%) \cdot\left([\mathrm{Mg}]+\left[\mathrm{SO}_{4}\right]\right) \cdot t(\mathrm{Y})
$$

where $C A \%$ is the percentage by weight of tricalcium aluminate $\left(3 \mathrm{CaO} \cdot \mathrm{Al}_{2} \mathrm{O}_{3}\right)$ in the cement, [Mg] and [ $\left.\mathrm{SO}_{4}\right]$ are the molar concentrations of magnesium and sulfates, respectively, in the test solution, and $t(y)$ is the test time in years. According to this model, the depth of attack is linear in time. The variability in the depths of attack were around $30 \%$ of the average. The equation was found to give satisfactory correlations with the results of field tests, in which the depth of penetrations were in the range of 0.8 to $2 \mathrm{~cm}$ after 5 years. The equation was used to calculate lifetimes of concrete exposed to groundwater of a known concentration of sulfate salts.

Concretes made with ordinary portland cements containing between 5 and $12 \% C_{3} A$, gave estimated lifetimes of between 180 to 800 years, with a probable lifetime of 400 years. When a sulfate resisting portland cement with $1.2 \% \mathrm{C}_{3} \mathrm{~A}$ was used, the minimum and probable lifetimes were estimated to be 700 years and 2500 years, respectively. These times were estimated based on the loss of one-half of the load-bearing capacity of a $1 \mathrm{~m}$ thick concrete section, i.e., $x_{s}$ of $50 \mathrm{~cm}$. The estimates involve an extrapolation based only on an empirical equation that has been shown to be reasonably predictive only during short-term testing. Atkinson, et al. [3.33], attempted to verify the equation by determining the extent of deterioration of concretes buried and exposed to the groundwater of a clay for 43 years. An alteration zone of about $1 \mathrm{~cm}$ was observed in the concretes which could be caused by several processes. Based on the tricalcium aluminate contents of the cements, equation no. 3.25 predicts that the thickness of the deteriorated region should be between 1 and 9 $\mathrm{cm}$. Therefore, it was concluded that the equation either gives a correct estimate or an overestimate of the rate of sulfate attack.

Later, the empirical model was modified by Shuman et al. [3.34], as follows;

$$
\mathrm{x}_{\mathrm{S}}=1.86 \times 10^{6} \mathrm{CA}([\mathrm{Mg}]+[\mathrm{SO} \underline{4}]) \mathrm{D}_{t} \cdot t
$$

where $D_{t}$ is the diffusion coefficient of sulfates in concrete. Introducing the value of $3 \times 10^{-7} \mathrm{~cm}^{2} / \mathrm{s}\left(3 \times 10^{-11} \mathrm{~m}^{2} / \mathrm{s}\right)$ into equation (3.25), equation (3.26) is derived. This model is based on the assumption that the rate of attack is proportional to the diffusion coefficient. The use of $3 \times 10^{-7} \mathrm{~cm}^{2} / \mathrm{s}\left(3 \times 10^{-11} \mathrm{~m}^{2} / \mathrm{s}\right)$ as the intrinsic diffusion coefficient of sulfates in the experimental concrete is questionable as the only report on measuring the diffusion coefficient for sulfates ions in cement- 
based materials gave a value of $6 \times 10^{-14} \mathrm{~m}^{2} / \mathrm{s}[3.35]$. It does not appear that equation $(3.26)$ has been validated by comparing the predicted depth of attack with either laboratory or field

studies.

\subsubsection{Shrinking Core Model}

A shrinking core model was developed for sulfate attack by Rasmuson et al. [3.36], using an approach described by walton et al. [3.16], In this approach sulfate ions move through degraded concrete to the interface of unreacted concrete, and then react with the hydration products of tricalcium aluminate to form expansive products such as ettringite. Mass transport equations are used, assuming a quasi-steady state, to predict the movement of sulfates in the concrete. The flux of sulfate ions, $N$, is given by:

$$
N=-D_{i}\left(C_{0} / x\right)
$$

where $C_{0}$ is the concentration of sulfate in the bulk solution, $D_{i}$ is the intrinsic diffusion coefficient, and $x$ is the depth of attack.

The rate of attack is given by the rate of mass transport divided by the concentration of solid tricalcium aluminate, $c_{a}$ :

$$
d x / d t=-N / C_{a}=D_{i} C_{0} / C_{a} x
$$

This model predicts that the rate of sulfate attack decreases with increasing amounts of tricalcium aluminate. Also, a $t^{1 / 2}$ dependence on the rate of attack is predicted.

\subsubsection{Mechanistic Model}

A mechanistic model has been developed by Atkinson and Hearne [3.37] for predicting the effect of sulfate attack on service life of concrete. The model is based on following assumptions:

(1) sulfate ions from the environment penetrate the concrete, by diffusion,

(2) sulfate ions react expansively with aluminates in the concrete, and

(3) cracking and delamination of concrete surfaces result from the expansive reactions.

Cracking and delamination of the concrete surface exposes a new surface to a concentration of sulfate ions near that of the groundwater sulfate concentration, rather than the smaller concentration resulting from diffusion. The model predicts that rate of sulfate attack will be largely controlled by the concentration of sulfate ions and aluminates, diffusion and 
reaction rates, and the fracture energy of concrete.

Relationships are developed for reaction kinetics, the

concentration of reacted sulfate as ettringite, the thickness of a concrete which spalls, the time for a layer to spall, and the degradation rate. The degradation rate ( $R$ ) is linear in time $(\mathrm{m} / \mathrm{s})$ and is given by:

$$
R=X_{\text {spall }} / T_{\text {spall }}=\left(E B^{2} C_{s} C_{0} D_{i}\right) /(\alpha \tau(1-v)
$$

where $\mathrm{x}_{\text {spall }}$ is the thickness of a spalled layer,

$\mathrm{T}_{\text {spall }}$ is the time for a layer to spall,

$E$ is Young's modulus,

$B$ is the linear strain caused by one mole of sulfate, reacted in $1 \mathrm{~m}^{3}$ of concrete,

$c_{s}$ is the sulfate concentration in bulk solution,

$C_{o}$ is the concentration of reacted sulfate as ettringite,

$D_{i}$ is the intrinsic diffusion coefficient of sulfate ions,

$\alpha_{0}$ is a roughness factor for fracture path (assumed to be 1.0),

$\tau$ is the fracture surface energy of concrete, and

$v$ is Possion's ratio.

Some of the data needed to solve the model needs to be obtained from laboratory experiments. Some of the parametric data to solve the model are not available for specific concretes and typical values must be used. The model appears to mathematically describe a wetting and drying process, in which concrete disintegration may be observed. For example, starks [3.38] observed that cracking and disintegration occurred during wetting and drying with sulfate-bearing waters.

The model by Atkinson and Hearne [3.37] predicts that the diffusion coefficient and the sulfate concentration of the groundwater are the most significant factors cortrolling the resistance to sulfate attack. However, it is doubtful that sulfate ions would be transported by diffusion when wetting and drying is the most important exposure conditions. convection and absorption are more likely to be the predominant transport processes. The linear time order indicates that the rate of attack is controlled by cracking [3.17].

In summary, the mechanistic model gives the same time order as the empirical model and thus both are in conflict with the shrinking core model. The shrinking core model would be applicable if diffusion was the rate controlling process which would most likely to occur when concrete is immersed in sulfatebearing water, e.g., seawater. The mechanistic and empirical models appear to be applicable when the degraded concrete surface separates from sound concrete which occurs during wetting and drying processes [3.39]. 


\subsubsection{Alkali-Aggregate Reactions}

Models for predicting the service-life of concrete experiencing alkali-aggregates reactivity have not been found. An approach for modeling such reactions is discussed in the following. A two step process may be formulated in which the first step involves reaction between reactive minerals in aggregates and hydroxide ions; followed by a second step involving the imbibition of water by the reaction products, resulting in the development of internal stresses in the concrete. If the concrete is wet then the two steps could occur essentially simultaneously. If the concrete is essentially dry, an pseudo-induction period would be observed, ending when sufficient water was present to activate the swelling process.

The first step may involve the diffusion of calcium, alkali and hydroxide ions in the pores of aggregates, which controls the rate of reaction. In principle, the diffusion processes controlling the rate of reaction can be modelled, although the diffusion coefficient may not be known. Modeling of the second step would involve mathematically describing the penetration and movement of water in concrete, which may involve both convection and absorption processes. If the overall process was diffusion controlled, the time order would be $t^{1 / 2}$. If the overall process was controlled by the movement of water and a pseudo-induction period involved, the time order could be complex varying between $1 / 2$ and 1 [3.17]. Experimental studies would likely be needed to obtain the parametric values to solve such a model.

\section{2 .4 Frost Attack}

The rate of frost attack is difficult to model from a theoretical position because of the lack of an adequate understanding of the mechanisms. An empirical model, however, has been described by shuman, et al. [3.34]. In the model, frost durability is modeled by empirically relating the decrease in dynamic modulus of elasticity of concrete to the percentage of entrained-air, waterto-cement ratio, and the number of freezing and thawing cycles using ASTM C 666 [3.40]. Based on the experimental results, changes in dynamic modulus of elasticity were taken to be linear when the number of freezing and thawing cycles was greater than 50. The amount of annual degradation, $R_{f t}$, based on the fraction of strength loss, is given by:

$$
R_{f t}=\left(N / T_{c}\right)\left[\left(0.05 / \Theta^{1 / 2}\right)-0.21 T_{r}\right]
$$

where $\mathrm{N}$ is the number of freezing and thawing cycles,

$\mathrm{T}_{\mathrm{c}}$ is the amount of experimental time required to reach a $50 \%$ decrease in dynamic modulus of elasticity,

$\Theta$ is the water content of the concrete, and $\mathrm{T}_{\mathrm{r}}$ is the unsaturated pore content of the concrete. 
The model predicts that the rate of degradation would have a linear time order dependence if the number of freezing and thawing cycles is essentially the same year by year.

The model assumes that during each freezing cycle that the concrete is critically saturated, which is a reasonable assumption only if the concrete is in some way essentially in continuous contact with water. Because most concrete is not continuously saturated the model should be modified to be of general applicability. A function which estimates the probability that concrete is critically saturated while subjected to freezing temperatures should be introduced into the model. Also, the model should be modified to consider the distribution and movement of water in a structure. Finally, it is recognized that ASTM C 666 [3.40] usually significantly overestimates the field damage caused by frost attack [3.41]. In summary, the model (equation no. 3.30) will likely substantially underestimate the service life of concrete subjected to frost attack.

A probabilistic model for predicting the service life of concrete structures subjected to frost attack was developed by Bryant and Mlakar [3.42]. The model gives the probability that an unit of concrete within a structure is saturated and subjected to freezing temperatures. Needed information on the number of annual freezing cycles are obtained from local weather data. The degree of saturation that an unit volume of concrete would experience is based on assuming that convection is the main transport process. Temperature and moisture distributions are predicted based on finite element modeling. The model appears to be only applicable to structures continuously partially immersed in water. Two applications of the model have addressed the depth of frost attack of the concrete of inland-water structures within a meter of the water line.

It appears that neither model adequately simulates the mechanism of frost attack on concrete in nuclear power plants; frost damage of the concrete would involve a moving interface, which is not addressed by equation no. 3.30 ; also, it would be associated with intermittent wetting and drying, not a continously wetting process as treated by the model by Bryant and Mlakar [3.42]. Therefore, neither model could be satisfactorly applied.

\section{2 .5 Leaching}

A model was developed by James and Lupton [3.43] for the dissolution of gypsum and anhydrite. It had the form:

$$
\mathrm{dM} / \mathrm{dt}=\mathrm{KA}\left(\mathrm{C}_{\mathrm{s}}-\mathrm{C}\right)^{\theta_{2} .6}
$$

where $M$ is the mass lost in time $t$ from an area $A, K$ is a dissolution rate "constant" linearly dependent on the flow 
velocities within laminar flow regimes, $c_{s}$ is the solution potential of water, $\mathrm{C}$ is the concentration of dissolved material at time $t$, and $\Theta$ is the kinetic order of the dissolution process. Jones [3.44] used the model to predict the rate of dissolution of portland cement mortar from a dam. The dissolution of both silica and calcium were experimentally determined to give secondorder kinetics. A loss of $0.8 \mathrm{~mm} /$ year of mortar was predicted at a flow velocity of $3 \mathrm{~m} / \mathrm{s}$, which in excellent agreement with the measured loss of $1 \mathrm{~mm} / \mathrm{y}$ at flow of $3 \mathrm{~m} / \mathrm{s}$. This model predicts that the rate of leaching has a linear time dependence.

A simple diffusion model was developed by Atkinson and Hearne [3.31], based on a shrinking core principle, for the leaching of calcium hydroxide from concrete. The model has the form:

$$
X=\left[2 D_{i}\left(C_{1}-C_{g w}\right) / C_{s}\right)^{1 / 2} t^{1 / 2}
$$

where $\mathrm{X}$ is the depth of leaching of $\mathrm{Ca}(\mathrm{OH})_{2}$,

$D_{i}$ is the intrinsic diffusion coefficient for $\mathrm{Ca}^{2+}$ in concrete,

$\mathrm{C}_{1}$ is the concentration of $\mathrm{Ca}^{2+}$ in the concrete pores, $\mathrm{C}_{\mathrm{gw}}$ is the concentration of $\mathrm{Ca}^{2+}$ in the groundwater, and $\mathrm{C}_{\mathrm{s}}^{\mathrm{gw}}$ is the concentration of solid $\mathrm{Ca}^{2+}$ in concrete.

As typical of diffusion models, this model predicts the rate has a $t^{172}$ dependence. It does not predict the effect of the velocity or chemistry of the groundwater on the leaching rate.

Another model was developed by Atkinson and Hearne [3.31], in which diffusion of leached $\mathrm{Ca}(\mathrm{OH})_{2}$ into the surrounding geology is rate controlling. It also predicts a $t^{1 / 2}$ rate dependence.

A model was developed by Pommersheim and clifton [3.17] to predict the rate of acid leaching of calcium hydroxide from concrete, which considered both diffusion and convection. The model predicts that if the attack is reaction controlled, which likely will occur with calcerous coarse aggregates, the rate of leaching will have a linear time dependence. With a siliceous aggregate, the process will likely be diffusion controlled with a $t^{1 / 2}$ time dependence.

\subsection{References}

3.1. J.R. Clifton, "Methods for Predicting Service Lives of Concrete," in Durability of Building Materials and Components, Proceedings of Fifth International Conference, E. \& F.N. Spon, London, pp. 361-373 (1990). 
3.2. G. Fagerlund, "Essential data for Service Life Prediction," in Problems in Service Life Prediction of Building and Construction Materials, ed. L.W. Masters, Martinus Nijhoff Publishers, Dordrecht, pp. 113-138 $(1985)$.

3.3. A. Neville, "Why we have concrete durability problems," in Concrete Durability: Katherine and Bryant Mather International Conference, ed. J.M. Scanlon, American Concrete Institute, pp. 21-30 (1987).

3.4. G. Frohnsdorff, I.W. Masters, and J.W Martin, "An Approach to Improved Durability Tests for Building Materials and Components." National Bureau of Standards, NBS Technical Note 1120 (1980).

3.5. E. Vesikari, "Service Life Design of Concrete Structures with Regard to Frost Resistance of Concrete," Nordic Concrete Research, Publication No. 5, 215-228, Norske Betongforening (Olso, 1986).

3.6. G.L. Kalousek, L.C. Porter, and E.J. Benton, "Concrete for Long-Term Service in Sulfate Environment," Cement and Concrete Research, Vol. 2 (1), 79-90 (1972).

3.7. E. Biczok, "Concrete Corrosion and Concrete Protection," Chemical Publishing Co. (New York, 1967).

3.8. L. Sentler, (1984) Stochastic Characterization of Carbonation of Concrete," in the 3rd International Conference on the Durability of Building Materials and Components, Technical Research centre of Finland, pp. 569-580 (1984)].

3.9. J. Martin, "Service Life Predictions from Accelerated Aging Tests using Reliability Theory and Life Testing Analysis," in Problems in Service Life Prediction of Building and Construction Materials, ed. I.W. Masters, Martinus Nijhoff Publishers, Dordrecht, pp. 191-212 $(1985)$.

3.10. E. Vesikari, "Service Life of concrete structures with Regard to Corrosion of Reinforcement," Technical Research Centre of Finland, Research Report 553 (1988).

3.11. J. Martin, "Accelerated Aging Test Design for Coating Systems," in Proc. 15th Inter. Conference on Organic Coatings Science and Technology, Athens, Greece, pp. 237-253 (1989). 
3.12. J. Martin and E. Embree, "Effect of Contaminants and Cure Time on EPDM Single-Ply Joint strength," J. Materials in Civil Engineering, 1, 151-168 (1989).

3.13. A. Siemes, A. Vrouwenvelder, and A. Beukel, "Durability of Buildings: A Reliability Analysis" Heron, 30, 3-48 (1985).

3.14. J.R. Clifton and L.I. Knab, "Service Life of Concrete," NISTIR 89-4086, National Institute of Standards and Technology (1989).

3.15. J. Pommersheim, and J.R. Clifton, "Prediction of Concrete Service-Life," Materials and Construction, 18, pp. 21-30 (1985).

3.16. J.C. Walton, L.E. Plansky, and R.W. Smith, "Models for Estimation of Service Life of Concrete Barriers in LowLevel Radioactive Waste Disposal," Report NUREG/CR-5542, U.S. Nuclear Regulatory Commission (1990).

3.17. J. Pommersheim, and J.R. Clifton, "Models of Transport Processes in Concrete," NISTIR 4405, National Institute of Standards and Technology (1990).

3.18. J.L. Beaton and R.F. Stratfull, "Environmental Influence of Corrosion of Reinforcing steel in concrete Substructures," Highway Research Board Record No. 14, pp. 60-78 (1963).

3.19. D.L Spellman and R.F. Stratfull, "Laboratory corrosion Test of steel in Concrete," California Division of Highways, Interim Report No. M\&R 635116-3 (September 1968).

3.20. K.C. Clear, "Time-To-Corrosion of Reinforcing steel in Concrete slabs, Volume 3: Performance After 830 Daily Salt Applications, FHWA-RD-76-70, Federal Highway Administration (April 1976).

3.21. K. Tuutti, "Corrosion of steel in Concrete," Swedish Cement and Concrete Research Institute, Stockholm (1982).

3.22. J.R. Clifton, L.I. Knab, E.J. Garboczi, and I.X. Xiong, "Chloride Ion Diffusion in Low Water-To-Solid Cement Pastes," NISTIR 4549, National Institute of Standards and Technology (April 1991).

3.23. M.I. Jacobs, "Diffusion Process," Springer-Verlag (New York, 1967). 
3.24. F.S. Merritt, "Mathematics Manual," McGraw-Hill Book Company, Inc. (New York, 1962).

3.25. Z.P. Bazant, "Physical Model for steel Corrosion in Concrete sea structures-Theory," ASCE Journal of the Structures Division, Vol. 105 (ST6), 1137-1153 (June 1979).

3.26 Z.P. Bazant, "Physical Model for steel Corrosion in Concrete Sea Structures-Application," ASCE Journal of the Structures Division, Vol. 105 (ST6) 1155-1166 (June 1979).

3.27. E.V. Subramanian and H.G. Wheat, "Depassivation Time of Steel Reinforcement in a chloride Environment - A oneDimensional Solution," Corrosion, Vol. 45, pp. 45-48 (1989).

3.28. R.F.Baker, "Initiation Period, in Corrosion of Steel in Concrete, pp. 22-55, RILEM Report, ed. Schiessl, Chapman and Hall (1988).

3.29. S.T. Wu and J.R. Clifton, "Analysis and Modeling of Corrosion of Steel in Prestressed Concrete, NBSIR 81-2390, National Bureau of Standards (November 1981).

3.30. S.T. Wu and J.R. Clifton, "Computational Models Developed for the Corrosion of Prestressing Steel," NISTIR 4455, National Institute of standards and Technology (March 1991).

3.31. A. Atkinson and I.A. Hearne, "an Assessment of the LongTerm Durability of concrete in Radioactive Waste Repositories," AERE-RI1465, Harwell, U.K. (1984)]

3.32. W.H. Harrison and D.C. Teychenne, "Sulphate Resistance of Buried Concrete: Second Interim Report on Long Term Investigation at Northwick Park, Building Research Establishment (Garston, 1981).

3.33. A. Atkinson, D.J. Goult, and J.A. Hearne, "An Assessment of the Long-Term Durability of Concrete in Radioactive Waste Repositories," Materials Research Society Symposium Proceedings: Scientific Basis for Nuclear Waste Management IX, Vol. 50, 239-246 (1986).

3.34. R. Shuman, V.V. Rogers, and R.A. Shaw, "The Barrier Code for Predicting Long-Term Concrete Performance," Waste Management 89, University of Arizona (1989).

3.35. J.W.T. Sprinks, H.W. Baldwin, and T. Thorvaldson, "Tracer Studies in set Portland Cement, Canadian Journal of Technology, Vol. 30, pp. 20-28 (1952). 
3.36. A. Rasmuson and M. Zhu, "Calculations of The Degradation of Concrete in a Final Repository for Nuclear Water," in Proceeding of NEA Workshop on Near-Field Assessment of Repositories for Low and Medium Level Radioactive wastes (Baden, Switzerland, 1987).

3.37. A. Atkinson and J.A. Herne, "Mechanistic Model for the Durability of Concrete Barriers Exposed to SulphateBearing Groundwaters," Materials Research Society Symposium Proceedings 176, pp. 149-156 (1990).

3.38. D. Stark, "Durability of Concrete in Sulfate-Rich Soils," Research and Development Bulletin RD097.01T, Portland Cement Association (Skokie, Illinois, 1989).

3.39. F.A. Lossing, "Sulfate Attack on Concrete Pavements in Mississippi," Highway Research Record No. 113, pp. 88-107 (1966).

3.40. "Standard Test Method for Resistance of Concrete to Rapid Freezing and Thawing," ASTM Designation C 666 (1991).

3.41. "Guide to Durable concrete," ACI 201.2R-5, ACI Manual of Concrete Practice, Part 1 (1990).

3.42. L.M Bryant and P.F. Mlakar, "Concrete Service Life," Report No. J650-88-003, U.S. Army Corps of Engineers, Waterways Experiment Station, Vicksburg, MS (1988).

3.43. A.N. James and A.R. Lupton, "Gypsum and Anhydrite in Foundation of Hydraulic Structures," Geotechnique, Vol. 28, No. 3, pp. 249-272 (1978).

3.44. A.N. Jones, "Preliminary Field studies of Rates of Dissolution of Hydrated Cement," Magazine of Concrete Research, Vol. 41, No. 148, pp. 155-162 (1989). 
In comparison to predicting the service life of new concrete, few studies on predicting the remaining service life of in-service concrete have been reported. In a sense, however, every inspection gives at least a qualitative life prediction, e.g., whether the structure needs repair or has adequate structural integrity to remain in-service until at least until the next inspection. Most of the reported studies have dealt with corrosion of concrete reinforcement, reflecting the magnitude and seriousness of corrosion problems.

\subsection{Models}

Browne [4.1] has developed a diffusion-based model and procedure for predicting the remaining service life of in-service reinforced concrete structures exposed to chloride ions. It only considers the initiation period, and thus assumes that the diffusion of chloride ions is the rate controlling process. The procedure for making predictions is:

(1) Samples are obtained from a concrete structure at different depths from the concrete surface and their chloride contents are determined.

(2) Use the following equation to obtain values of $\mathrm{C}_{0}$ and $\mathrm{D}_{\mathrm{cl}}$ :

$$
C(x, t)=C_{0}\left[1-\operatorname{erf}\left(x / 2 D_{c l} \cdot t\right)^{3 / 2}\right]
$$

where $c(x, t)$ is the chloride concentration at depth $x$ after time $t$, for an equilibrium chloride concentration of $c_{0}$ at the surface; $D_{c l}$ is the chloride ion diffusion coefficient; and erf is the error function.

(3) Once the values of $C_{0}$ and $D_{c l}$ are obtained, then the chloride ion concentration at any distance from the surface can be calculated using equation (4.1).

(4) A chloride ion concentration of $0.4 \%$, based on weight of cement, is used by Browne as the threshold value. The time to reach the threshold concentration at the depth of the reinforcing steel gives the remaining service life.

Hookham [4.2] used two empirical models described by Vesikari [4.3] to predict service life of an ore dock originally constructed in 1909. The "carbonation model" has the following formulation:

$$
t_{c}=L / R_{c}
$$


where $t_{c}$ is the time to full cover carbonation, $L$ the remaining uncarbonated cover, $\mathrm{R}_{\mathrm{c}}$ is the rate of carbonation. At the dock, the rate of carbonation, assuming linear diffusion, was calculated to be $0.28 \mathrm{~mm} / \mathrm{y}$. L was estimated to be $9.5 \mathrm{~mm}$. Using equation no. 4.2 , the time-to-full carbonation was calculated to be approximately 34 years. Prediction of remaining service life with respect to chloride attack was modeled using the relationship:

$$
t_{2}=k_{c} * k_{e} * L^{2}+k_{a} * L
$$

where $t_{2}$ is the service in years, $L$ is the thickness of concrete cover in $\mathrm{cm}, \mathrm{k}_{\mathrm{c}}$ the quality coefficient of the concrete, $\mathrm{k}_{\mathrm{e}}$ is the coefficient of environment, and $k_{a}$ is the coefficient of active corrosion. Based on the report by vesikari [4.3], values of 7.59 , 0.85 , and 4.0 were used for $k_{c}, k_{e}$, and $k_{a}$, respectively. Note that $\mathrm{L}$ is now in units of $\mathrm{cm}$, so that $\mathrm{L}=0.95 \mathrm{~cm}$. The predicted remaining life was 10 years.

Another approach for predicting the remaining service life of concrete when carbonation is the major deleterious process is to use the square root of time principle [4.4]. The depth of carbonation, $x_{c}$, is given by:

$$
x_{c}=k_{c} t^{1 / 2}
$$

By measuring the depth of carbonation in concrete, $\mathrm{k}_{\mathrm{c}}$, can be determined and then the time for carbonation to reach the reinforcing steel predicted. In a damp environment, equation (4.4) may be conservative as the rate of carbonation could be much less than that predicted by $t^{1 / 2}$ if the pores of the concrete become water saturated [4.5]. Pocock discussed [4.6] the application of this relationship in predicting the remaining service life of concrete in nuclear power facilities. This method considers only the initiation period.

\subsection{Corrosion Measurements}

The measurement of corrosion currents of steel reinforcement in concrete have been used by both Andrade and coworkers [4.7-4.9] and by clear [4.10] in estimating the remaining service life of reinforced concrete in which corrosion is the limiting degradation process. Both used the polarization resistance technique to measure corrosion currents.

Andrade [4.7-4.9] adopted Tuutti's conceptual model and used measurements of corrosion current to estimate the remaining service life (Fig. 4.1). Her model considers reduction in steel section as the significant consequence of corrosion, instead of cracking or spalling of the concrete. 
The corrosion current was converted to reductions in the diameter of reinforcing steel by the relationship:

$\Theta(t)=\Theta_{i}-0.023 * i_{\text {corr }} * t$

where $\Theta(t)$ = the rebar diameter at time $t$ (mm),

$\Theta_{i}=$ the initial diameter of the rebar (mm),

$i_{\text {corr }}=$ the corrosion rate $\left(\mathrm{A} / \mathrm{cm}^{2}\right)$,

$t=$ the time after the beginning of the propagation period (years), and

$0.023=$ the conversion factor of $\mathrm{A} / \mathrm{cm}^{2}$ into $\mathrm{mm} /$ year.

The results were converted into service predictions by modeling the effects of reduction in cross section of the reinforcement on load capacity of the reinforced concrete. Service life predictions were reported for examples in which the concrete had a compressive strength of $20 \mathrm{MPa}$ and the yield strength of the steel was $400 \mathrm{MPa}$. Safety factors of 1.5 and 1.1 were used for concrete and steel design strengths, respectively. Fig. 4.2 shows the reduction of cross section as a function of bar diameter and corrosion rates. The predicted decrease in the bending moment capacity of reinforced concrete beams as a function of corrosion is shown in Fig. 4.3. Similar figures were constructed for shear and axial forces in beams.

Based on the combination of laboratory, outdoor exposure, and field studies, Clear [4.11] suggested the use of the following relationships (which assume constant corrosion rates with time) between corrosion rates, which he designated as $I_{\text {CORR, }}$ and remaining service life:

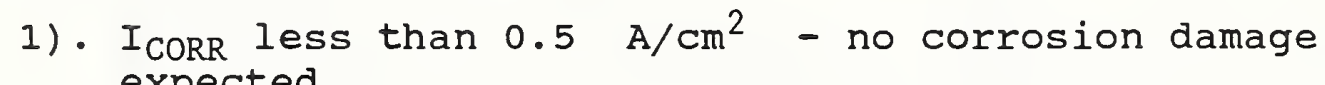
expected.

2). ICORR between 0.5 and $2.7 \mathrm{~A} / \mathrm{cm}^{2}$ - corrosion damage possible in the range of 10 to 15 years.

3). ICORR between 2.7 and $27 \mathrm{~A} / \mathrm{cm}^{2}$ - corrosion damage expected in 2 to 10 years.

4). ICORR in excess of $27 \mathrm{~A} / \mathrm{cm}^{2}$ - corrosion damage expected in 2 years or less.

These criteria appear to be in general agreement with the predictions given by Andrade.

To make reliable prediction of service life, based on measuring corrosion currents, the effect of any changes in ambient conditions must be considered. Presumably, indoor conditions of nuclear power structures would remain fairly constant and thus 



Figure 4.1 Effect of Corrosion on the Diameter and Cross Section of Reinforcing Steel Bars, with Diameters of $10 \mathrm{~mm}$ and $20 \mathrm{~mm}[4.9]$. 
I is the corrosion rate

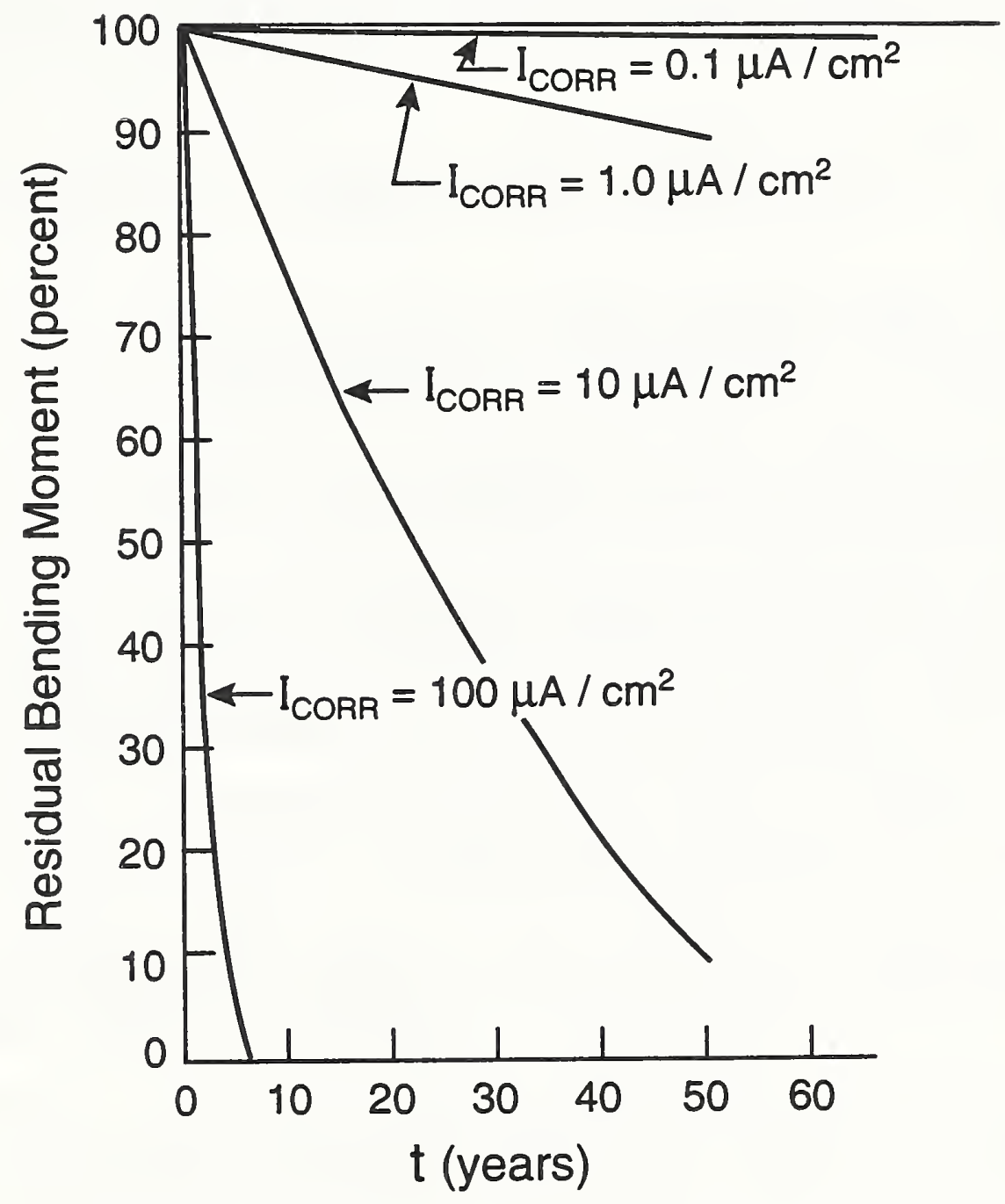

Figure 4.2 Reduction in Bending Moment Capacity of Concrete Beam by corrosion of Reinforcing steel [4.9]. 
have little effect on corrosion currents. However, significant changes in corrosion currents induced by changes in outdoor conditions are to be expected.

\subsection{References}

4.1. R.D. Browne, "Mechanisms of Corrosion of Steel in Concrete," in Concrete in Relation to Design, Inspection, and Repair of offshore and Coastal Structures, ACI SP-65.

4.2. C.J. Hookham, "Rehabilitation of Great Lakes steel's No. One Dock," ACI Sympsoium of Durability of Concrete, in press.

4.3. E. Vesikari, "Service Life of Concrete structures with Regard to Corrosion of Reinforcement," Technical Research Centre of Finland Research Report No. 553 (Espoo, August 1988).

4.4. H. Klopper, "Carbonation of External Concrete and How to Combat It," Bentenschutz and Bausanierung, Vol. 1, No. 3 (1978).

4.5. R.F.M Bakker, "Initiation Period," Chapter Three in Corrosion of steel in Concrete, ed. P. Schiessel (Chapman and Hall, 1988.

4.6. D.C. Pocock, "Prediction of Possible Reinforcement Corrosion during Remaining Life in Concrete structures at Nuclear Installations," Symposium on the Review of Safety at Magnox Nuclear Installations, London (March 9, 1989).

4.7. J.R. Rodriquez and C. Andrade "Load-Bearing Capacity Loss in Corroding structures," presented at ACI 1990 spring Convention, Toronto, in press.

4.8. C. Andrade, C. Alonso, J.A. Gonalez, and J. Rodriguez, "Remaining Service Life of Corroding structures," IABSE Report 57/1, Durability of Structures, 359-364 (1989).

4.9. C. Andrade, M.C. Alonso, and J.A. Gonzales, "An Initial Effort to Use the Corrosion Rate Measurements for Estimating Rebar Durability," ASTM STP Corrosion Rates of Steel in Concrete, pp. 29-37 (1990).

4.10. K.C Clear, "Measuring Rate of Corrosion of Steel in Field Concrete Structures," Paper No. 88-0324, 68th Annual Meeting of Transportation Research Meeting (1989).

4.11. K.C. Clear, "Measuring Rate of Corrosion of steel in Field Concrete Structures," Kenneth C. Clear, Inc. Sterling, VA (January 1989). 
The prediction of the remaining service life of concrete materials in nuclear power facilities essentially involves determining the present state of the concrete and then estimating the time required for the concrete to degrade to the failure state. In estimating the time-to-failure, the specific process(es) responsible for the degradation needs to be identified and the degradation rates for the process(es) determined. Proposed approaches for estimating the degradation rate and their use in predicting remaining service lives are described in this chapter.

\subsection{Time Order Approach}

\subsubsection{Development of Approach}

The amount of degradation of a concrete is dependent on the environment, geometry of the structure, properties of the concrete, the specific degradation processes, and the concentration of the aggressive specie(s). In the time order approach presented here, it is assumed that these factors are invariant and thus can be represented by a constant, $\mathrm{k}_{\mathrm{d}}$. It is recognized that the climate changes from season to season but it is assumed that the variation between years smooths out over several decades so that only the number of years are represented by the time function, $t_{\mathrm{y}}$. In this case $k_{\mathrm{d}}$ will not change from year to year.

The amount of degradation, $A_{d}$, can be represented by [5.1]:

$$
A_{d}=k_{d} t_{y}^{n}
$$

where $A_{d}$ is the amount of accumulative deterioration at time

$t_{y}$ (years), and

$\mathrm{n}$ is the time order.

The overall rate of degradation, $R_{d}$ is given by:

$$
R_{d}=n k_{d} t_{y}^{n-1}
$$

Equation (5.2) indicates that when $\mathrm{n}<1$, the rate of degradation decreases with time; when $n=1$, the rate is constant; and when $n$ $>1$, the rate increases with time.

Defining $A_{d f}$ as the amount of damage-at-failure, and rearranging, equation no 5.1 becomes:

$$
t_{y f}=\left(A_{d f} / k_{d}\right)^{1 / n}
$$


where $t_{y f}$ is the time to failure. The remaining service life is obtained by subtracting the age of the concrete when the inspection was made from $t_{y f}$.

The value of $n$ is $1 / 2$ for a diffusion controlled process and 1 for a reaction controlled process [5.1]. If both convection and diffusion are involved in the transport of a reactive substance, $n$ could have a value between $1 / 2$ and 1 . The effect of capillary movement or sorption on $n$ needs to be determined. The value of $n$ can be determined by mathematical modelling, by measuring the amount of degradation of concrete at different ages, or possibly by experimental studies. Some values of $n$, from models described in this report, are:

* sulfate attack (wetting and drying): $n=1$

* carbonation: $n=1 / 2$

(immersed): $n=1 / 2$

* diffusion of chloride ions: $n=1 / 2$

* active corrosion of steel reinforcement: $n=1$

* acid attack (siliceous aggregate): $n=1 / 2$

* frost attack: $n=1$

\subsubsection{Example of Application}

The value of $\mathrm{n}$ is known to be $1 / 2$ for carbonation [5.2] and the remaining service life of reinforced concrete, considering only the initiation period, is easily obtained from knowledge of the age of the concrete, the depth of carbonation, and the depth of the reinforcing steel. The depth of carbonation can be obtained using a phenolphthalein indicator solution and the depth of the reinforcing steel measured during inspection. If the average depth of carbonation was $24 \mathrm{~mm}$ after 36 years and the average concrete cover over the reinforcing bars was $48 \mathrm{~mm}$, the time-tofailure would be:

$$
\mathrm{k}_{\mathrm{d}}=\mathrm{A}_{\mathrm{d}} / \mathrm{t}_{\mathrm{y}}^{\mathrm{n}}=24 / 36^{1 / 2}=4 \mathrm{~mm} / \mathrm{y}^{1 / 2} \text {, }
$$

and substituting the value for $\mathrm{k}_{\mathrm{d}}$ in equation (5.3)

$$
t_{y f}=(48 / 4)^{2}=144 \text { years. }
$$

Since the concrete was 36 years old at the time of inspection, the predicted remaining service life would be around 108 years. If the degradation had occur with $n=1$, the remaining service life would only be 36 years, while if $\mathrm{n}=2$, only 14 years would remain. These results indicate the importance of properly determining the value of the time order $n$.

Several forms of the depth of carbonation and the depth of the concrete cover over the reinforcement could be used including 
average depth, minimum depth, and maximum depth. If the distribution in the depth of carbonation and the depth of cover of concrete over the reinforcement were known, a probabilistic distribution of remaining life could be estimated.

The model developed by Browne [5.3] for predicting the remaining service life of in-service reinforced concrete structures exposed to chloride ions, follows a somewhat similar approach to that used in the carbonation example. As described in section 4.1, the chloride ion diffusion coefficient is first determined based on analyzing specimens of the concrete taken from different locations for chloride contents. Then the diffusion coefficient is used to estimate the time for the threshold concentration to reach the depth of the reinforcement. Both approaches are similar in that first the depth of degradation (in these cases, the depth of intrusion) is determined and then a parameter describing the rate of degradation is calculated. This parameter is then used in predicting the age of the concrete at failure.

The time order approach also can be used for predicting the remaining service life of concrete degraded by sulfate attack., The value of $n$ would be either 1 or $1 / 2$ depending on the type of sulfate exposure. If $\mathrm{n}$ is 1 , the solution involves a simple linear mathematical extrapolation.

\subsubsection{Recommendations for Further Development}

If the value of $\mathrm{n}$ is known, the time order method appears to be $a$ straightforward approach for predicting the remaining life of inservice concrete, when one process is rate controlling. Its applicability to specific degradation process should be evaluated by additional modeling which, if possible, is supplemented by field and experimental studies. Another area which should be studied is the applicability of this approach to the case where a series of individual degradation processes occur simultaneously, with different time orders, but with no predominant rate controlling process. Then, the feasibility of applying the time order method when more than one degradation process is simultaneously occurring should be determined. Also, procedures need to be develop to deal with severe changes, either transient or permanent, in the environment.

\subsection{Dealing with Cyclic Processes}

The effect of degradation processes which involve distinct cyclic events may be predicted based on estimating the number of past degradation cycles to which concrete has been subjected. For example, frost attack occurs when concrete is critically saturated and simultaneously exposed to freezing temperatures. If local weather data is available for the past service years of the concrete, the number of times the concrete was exposed to freezing temperatures could be estimated and correlated with the 
amount of degradation. Then assuming that the future temperature patterns follow the past patterns, the years required to reach failure could be predicted. The applicability of this model could possibly be increased by developing probabilistic methods for dealing with fuzzy weather data, e.g., weather data which is from a sufficiently remote source so that the degree of correlation with the micro-climate of the concrete is not known with high certainty, or if weather data is available for only a part of the concrete's past service life.

\subsection{Predictions Based on Estimating Original Service Life}

Situations may be encountered in which the remaining service life of concrete can only be estimated by predicting its original life using a service-life model, such as described in section 3.5. such a situation could arise where the concrete cannot be inspected or samples taken due to its inaccessibility or to potential serious hazards involved with its inspection. This would necessitate obtaining or estimating the values of the materials properties require to solve the model, e.g., diffusion coefficients for chloride ions. It is unlikely that all the required data would be available, especially data on transport properties of the concrete. Useful data probably could be obtained by testing concrete specimens which are prepared using the same mix proportions and curing conditions as reported for the in-service concrete. As a last resort, data from the characterization of a decommissioned nuclear power plant could be judiciously chosen for input into the models. After the required data is obtained, the appropriate service-life model could be solved. The predicted original life minus the age of the concrete would give its estimated remaining service life. obviously, this is not a desirable approach for predicting remaining service lives because of the large uncertainties which invariably would be associated with the estimates. Nevertheless, it provides a reasonable approach when data can not be directly obtained by inspecting either a structure or some of its critical concrete elements.

\subsection{Approaches for Other Major Degradation Processes}

Generic approaches for predicting the remaining lives of concrete have been discussed as well as their applications to several degradation processes including the corrosion initiation period involving the intrusion of carbon dioxide and chloride ions, sulfate attack, and frost attack. The corrosion propagation period and distresses caused by alkali-aggregate reactivity, however, are not addressed by the generic approaches. Because of importance of these processes, the feasibilities of predicting their effects on the lives of concretes are discussed. 
As discussed in section 3.5.1.3, the propagation period is the period of active corrosion according to the conceptual model for corrosion of reinforcement. This period is considered to end when the reinforced concrete fails because of corrosion. Developing ways to predict the remaining life of reinforced concrete undergoing active corrosion is an area of active research.

Andrade and coworkers [5.4-5.6] and Clear [5.7] have developed methods for estimating the remaining life of reinforced concrete undergoing active corrosion. Both approaches use the polarization resistance technique to measure corrosion currents. The specific details of the methods are given in section 4.2 .

\subsubsection{Alkali-Aggregate Reactivity}

At present, a technical basis does not exist for quantitatively predicting the effects of alkali-aggregate reactivity on the life of concrete. Only the likelihood that an aggregate will undergo expansive reactions with alkalies can be predicted with any reasonable reliability. Tests for determining if an aggregate is potentially reactive are discussed in section 2.3.4. If the manifestation of distress by aggregate reactivity is controlled by the intrusion of water, to cause swelling of the reaction products, the rate of the development of distress possibly could be predicted based on modeling the water intrusion process.

\subsection{References}

5.1. J. Pommersheim, and J.R. Clifton, "Models of Transport Processes in Concrete," NISTIR 4405, National Institute of Standards and Technology (1990).

5.2. R. Turriziani, "Internal Degradation of Concrete: AlkaliAggregate Reaction. Reinforcement steel Corrosion," 8th International symposium on Chemistry of Cement, Vol 1 , 388-442 (Rio de Janeiro, 1986).

5.3. R.D. Browne, "Mechanisms of Corrosion of steel in Concrete," in Concrete in Relation to Design, Inspection, and Repair of Offshore and coastal structures, ACI SP-65.

5.4. J.R. Rodriquez and C. Andrade "Load-Bearing Capacity Loss in Corroding Structures," presented at ACI 1990 spring Convention, Toronto, in press.

5.5. C. Andrade, C. Alonso, J.A. Gonalez, and J. Rodriguez, "Remaining Service Life of Corroding Structures," IABSE Report 57/1, Durability of Structures, 359-364 (1989). 
5.6. C. Andrade, M.C. Alonso, and J.A. Gonzales, "An Initial Effort to Use the Corrosion Rate Measurements for Estimating Rebar Durability," ASTM STP Corrosion Rates of steel in Concrete, pp. 29-37 (1990).

5.7. K.C Clear, "Measuring Rate of Corrosion of steel in Field Concrete Structures," Paper No. 88-0324, 68th Annual Meeting of Transportation Research Meeting (1989). 
This report is based on a study by the National Institute of Standards and Technology which analyzed methods for predicting the remaining service lives of concrete materials of nuclear power facilities. The study consists of two major activities: (1) the evaluation of models which can be used for predicting the remaining service life of concrete exposed to the major environmental stresses and aging factors; and (2) the evaluation of accelerated aging techniques and tests which either provide data for service life models or which themselves can be used to predict the remaining service life of existing concrete.

Identification and an understanding of expected degradation processes is necessary to select or, if necessary, to develop methods and models for predicting the life of affected concretes. Possible significant degradation processes for the concrete of nuclear power facilitates are corrosion of reinforcement, sulfate attack, alkali-aggregate reactions, frost attack, leaching, radiation, salt crystallization, and microbiological attack. The first three processes are considered to be the most likely to have an serious effect on the condition of the concrete.

Methods which are often used for predicting the service lives of construction materials include i) estimates based on experience, ii) deductions from performance of similar materials, iii)

accelerated testing, iv) applications of reliability and stochastic concepts, and v) mathematical modeling based on the chemistry and physics of degradation processes. Although these approaches are discussed separately in this report, they often are used in combination. The most promising methods are considered to be accelerated testing, applications of reliability and stochastic concepts, and use of mathematical models. Models for corrosion, sulfate attack, frost attack, and leaching were identified and analyzed. While no model was identified for distress caused by alkali-aggregate reactions, an approach for modeling the process was outlined.

In comparison to predicting the life of new concrete, few studies on predicting the remaining service life of in-service concrete have been reported. Most of the reported studies have dealt with corrosion of concrete reinforcement, reflecting the magnitude and seriousness of corrosion problems. Approaches which could be used in predicting remaining service lives are proposed and recommendations for their further development given.

It appears that the most promising approach for predicting the remaining service life of concrete involves the application of mathematical models of the degradation process. It is recommended that theoretical models be developed, rather than relying solely on empirical models. Many advantages of this approach are apparent, including more reliable predictions, far 
less data needed, and the theoretical models would have wider applications, e.g., are applicable to a broad range of environmental conditions. Deterministic and stochastic models should be combined to give realistic predictions of the service life of an engineering material. Purely stochastic models will probably have limited application because of the lack of adequate data bases to determine the statistical parameters. Accelerated tests do not provide a direct method for making the life predictions, but can be useful in obtaining data required to support the use of analytical models. 


\section{ACKNOWLEDGEMENTS}

The author gratefully acknowledge the sponsorship of the U.S. Nuclear Regulatory Commission for this report. The assistance of Dr. Dan Naus, Oak Ridge National Laboratory, Dr. Gunter Arndt, Nuclear Regulatory Commission, Dr. Bruce Ellingwood, John Hopkins University, and Dr. Geoffrey Frohnsdorff, National Institute of standards and Technology, who diligently read the paper and made suggestions which significantly improved the report are greatly appreciated. 



\title{
4. TITLE AND SUBTITLE
}

\author{
Predicting the Remaining Service Life of Concrete
}

5. AUTHOR(S)

James R. Clifton

6. PERFORMING ORGAMIZATION (IF JOINT OR OTHER THAN MIST, SEE INSTRUCTIONS)

U.S. DEPARTMENT OF COMMERCE

MATIONAL INSTITUTE OF STANDARDS AND TECHMOLOQY

GATTHERSBURQ, MD 20890

7. CONTRACT/GRANT MUMBER

8. TYPE OF REPORT AND PERIOD COVERED

9. SPONSORINO ORGANIZATION MAME AND COMPLETE ADDRESS (STREET, CITY, STATE, ZIP)

Oak Ridge National Laboratory

U.S. Department of Energy

Oak Ridge, TN 37831

\section{SUPPLEMENTARY NOTES} 11. ABSTRACT (A 200-WORD OR LESS FACTUAL SUMMARY OF MOST SIGMIFICANT INFORMATION. IF DOCUMENT INCLUDES A SIGMIFICANT BIBLOGRAPHY O
UTERATURE SURVEY, MENTION IT HERE)

Nuclear power plants are providing, currently, about 17 percent of the U.S. electricity and many of these plants are approaching their licensed life of 40 years. The U.S. Nuclear Regulatory Commission and the Department of Energy's Oak Ridge National Laboratory are carrying out a program to develop a methodology for assessing the remaining safe-life of the concrete components and structures in nuclear power plants. This program has the overall objective of identifying potential structural safety issues, as well as acceptance criteria, for use in evalutions of nuclear power plants for continued service. The National Institute of Standards and Technology (NIST) is contributing to this program by identifying and analyzing methods for predicting the remaining life of in-service concrete materials.

This report examines the basis for predicting the remaining service lives of concrete materials of nuclear power facilities. Methods for predicting the service life of new and in-service concrete materials are analyzed. These methods include 1) estimates based on experience, 2) comparison of performance, 3) accelerated testing, 4) stochastic methods, and 5) mathematical modeling. New appraoches for predicting the remaining service lives of concrete materials are proposed and recommendations for their further development are given.

Degradation processes are discussed based on considerations of their mechanisms, likelihood of occurrence, manifestations, and detection. They include corrosion, sulfate attack, alkali-aggregate reactions, frost attack, leaching, radiation, salt crystallization, and microbiological attack.

12. KEY WORDS (6 TO 12 ENTRIES; ALPHABETICAL ORDER; CAPITALZE ONLY PROPER MAMES; AND SEPARATE KEY WORDS BY SEMICOLONS)

Accelerated testing; alkali-aggregate reactions; concrete; corrosion; modeling; Nuclear Power Plants; service life; sulfate attack 


